\title{
COLIGAÇÕES ELEITORAIS: TENDÊNCIAS E RACIONALIDADES NAS ELEIÇÕES FEDERAIS E MAJORITÁRIAS ESTADUAIS (1990-2010) ${ }^{1}$
}

\author{
Geralda Luiza de Miranda
}

\begin{abstract}
RESUMO
O estudo avalia a influência da racionalidade que orienta as estratégias coligacionistas estabelecidas na disputa majoritária federal sobre as configuradas nas eleições para a Câmara, Senado e governadorias, no período 19902010. A hipótese que orienta a análise é que, dado o surgimento de incentivos institucionais e políticos, os partidos replicam, nas alianças estabelecidas nas últimas, as preferências e resistências que imprimiram na primeira. Na análise dos dados, são tomadas como unidades de análise as coligações e as alianças, e os partidos são classificados em relevantes e micros. Verifica-se tendências consistentes na participação eleitoral dos dois tipos de partidos e, no que se refere à racionalidade das estratégias coligacionistas, padrões de comportamento diferenciados entre os partidos, sendo que os principais competidores pelo cargo presidencial e seus aliados mais leais replicam, nas coligações estabelecidas para os outros cargos, a mesma racionalidade que imprimiram nas coligações da disputa presidencial. Esse comportamento é traduzido em uma resistência política que se sobrepõe à tradicional resistência ideológica nas estratégias coligacionistas.
\end{abstract}

PALAVRAS-CHAVE: coligações; eleições; Câmara dos Deputados; Senado Federal; governadoria.

\section{INTRODUÇÃO}

As coligações partidárias têm tido uma trajetória relativamente instável no sistema político brasileiro. Elas foram permitidas nas eleições de 1950 a 1962, proibidas pela Lei Orgânica dos Partidos Políticos, de 1971, e liberadas a partir das eleições de 1986. De 1986 a 1998, os partidos foram proibidos de constituir coligações incongruentes para a Câmara dos Deputados, em relação às firmadas para as governadorias. Nas eleições de 2002 e 2006, o Tribunal Superior Eleitoral (TSE) instituiu a verticalização: os partidos que integrassem coligações presidenciais adversárias não poderiam coligar-se nas disputas para os outros cargos (federais ou estaduais). Contrariados em suas preferências, os parlamentares aprovaram, em 2006, uma emenda constitucional (n. 52) que instituiu a não obrigatoriedade

\footnotetext{
1 Uma versão preliminar deste estudo foi apresentada no $6^{\circ}$ Congreso Latinoamericano de Ciencia Política da Alacip, realizado em Quito, Equador, em junho de 2012. Agradeço as contribuições recebidas naquela ocasião, assim como o apoio da Capes para minha participação no evento, e, especialmente, as críticas e sugestões dos pareceristas anônimos da Revista de Sociologia e Política que muito contribuíram para a melhoria da argumentação. Agradeço também a Yan de Souza Carreirão e a Rogério Schmitt por me cederem os dados das coligações realizadas nas eleições de 1990 para a Câmara e o Senado. Sem a generosidade de ambos, o escopo atual deste artigo não teria sido possível.
}

de manter-se os mesmos parceiros de coligação nos diversos pleitos.

Essa instabilidade institucional denota não apenas a existência de um embate político em torno do formato que se deve imprimir ou manter no sistema partidário, mas também a centralidade que as coligações ocupam nos cálculos de sobrevivência política dos partidos. Embora não se possa dizer que esse embate se restrinja ao atual período democrático, certamente foi nessa conjuntura que ele adquiriu contornos mais definidos e um caráter mais conflituoso. Duas agendas de pesquisa focadas nas coligações explicitam os parâmetros da controvérsia.

A primeira agenda foi aberta pelo estudo pioneiro de Soares (1964). No entendimento do autor, ao se coligarem, os partidos estariam orientados por duas racionalidades: a do "esforço mínimo" e a da "resistência ideológica". Eles fariam coligações visando maximizar votos, empreendendo o menor esforço possível, mas esse cálculo seria restringido ou equilibrado por considerações de natureza ideológica: partidos com ideologias ou enraizamento socioeconômicos distintos apresentariam maior resistência para compor as mesmas coligações, pois esse curso de ação representaria risco de perdas futuras em termos de votos.

A segunda agenda foi aberta por Lima Júnior (1983) 
e Lavareda (1991). Refere-se aos parâmetros do cálculo coligacionista: se nacional ou estadual, remetendo, nessa discussão, para a vinculação das estratégias estabelecidas nas disputas legislativas (proporcionais) às configuradas nas eleições executivas (majoritárias). Qualificando a tese de esforço mínimo, Lima Júnior chama a atenção para uma "racionalidade contextual", isto é, os cálculos dos partidos para as eleições proporcionais federais estariam referidos a elementos próprios da dinâmica de cada um dos subsistemas partidários estaduais e não aos da dinâmica partidária nacional. Lavareda, por outro lado, afirma que haveria um esforço por parte dos partidos em incorporar, nas estratégias coligacionistas para as eleições proporcionais federais, elementos relacionados à dinâmica da disputa majoritária estadual.

As teses de Soares (1964), Lima Júnior (1983) e Lavareda (1991) foram amplamente testadas por referência tanto às eleições do período 1950-1962 quanto às que ocorreram após 1986. No que se refere às teses de esforço mínimo e resistência ideológica, há relativo consenso quanto à sua validade nos dois períodos. Embora a primeira tenha sofrido qualificações importantes, a constatação de sua vigência tem sido verificada de diversas perspectivas e por diferentes técnicas de análise de dados; a validade da segunda, no entanto, ainda pode ser fortalecida pelo uso de técnicas diferentes de análise de dados, de forma a qualificar tanto sua evolução ao longo do período atual, quanto sua real incidência em termos temporais e partidários.

A agenda de pesquisa aberta por Lima Júnior (1983) e Lavareda (1991) foi ampliada e tem produzido achados mais controversos. Embora haja consenso de que a racionalidade que orienta o cálculo coligacionista nas eleições proporcionais federais é influenciada por elementos da disputa majoritária estadual, conforme argumentado por Lavareda, diversos estudos têm buscado avaliar também a influência da dinâmica das eleições presidenciais nas estratégias coligacionistas para os legislativos (federal, estadual e até municipal). A importância do debate é revelada pela premissa que o orienta: a influência da dinâmica majoritária estadual sobre as disputas legislativas federais afeta negativamente a dinâmica entre o poder Executivo e o poder Legislativo, na medida em que imprime na representação congressual um caráter federativo, isto é, orientado para os interesses estaduais; ao contrário, a influência da dinâmica majoritária federal propiciaria melhores condições de governabilidade, na medida em que constituiria, desde as eleições, alinhamentos partidários nacionais em torno das políticas propugnadas pelo futuro presidente e denotaria coordenação nacional das estratégias eleitorais por parte dos partidos.

De forma sucinta, os estudos dessa segunda agenda de pesquisa têm apontado articulações complexas nas estratégias coligacionistas do atual período democrático: na formação das coligações para as eleições legislativas federais, elementos relativos à dinâmica majoritária estadual parecem estar sendo, em alguma medida, equilibrados com aqueles referidos à dinâmica majoritária federal. Se a consideração dos primeiros, por parte dos partidos, não é novidade nas análises sobre o sistema político brasileiro (SHUGAR \& CAREY, 1992; MAINWARING, 1993; 1999; ABRUCIO, 1998; SAMUELS, 2003), em virtude de incentivos políticos e institucionais, a consideração dos últimos pode ser esperada em virtude da emergência desses mesmos incentivos a partir de 1994.

A discussão desenvolvida neste artigo insere-se nesse debate. A partir da análise das coligações estabelecidas para a Presidência da República, Câmara dos Deputados, Senado Federal e governadorias, no período de 1990 a 2010, busca-se oferecer contribuições nas duas agendas de pesquisa. A hipótese que orienta a análise é que, dado o surgimento de incentivos institucionais e políticos, os partidos replicam, nas eleições legislativas federais e nas majoritárias estaduais, a mesma racionalidade que imprimem nas eleições majoritárias federais. Ao verificar-se a bipolarização da disputa presidencial entre duas coalizões eleitorais, traduzida em uma resistência política nas estratégias coligacionistas, busca-se avaliar se essa resistência é replicada nas coligações estabelecidas para os cargos legislativos federais e majoritários estaduais e seu grau de aproximação com a tradicional resistência ideológica.

$\mathrm{Na}$ análise dos dados, recorre-se a técnicas ainda não utilizadas nos estudos sobre as coligações em eleições federais e estaduais. Primeiro, toma-se como unidades de análise tanto as coligações, tal como formalizadas em cada eleição, quanto as alianças, isto é, os pares de partidos em uma mesma coligação, o que permite uma avaliação mais acurada de suas preferências e resistências quanto aos parceiros de coligação $^{2}$. Segundo, parte-se da premissa de que a análise da racionalidade presente na disputa pelos cargos federais pode ser feita de forma mais parcimoniosa se forem considerados apenas os partidos que têm nesse nível da competição política uma atuação privilegiada. Para isto, utiliza-se a classificação dos partidos proposta por Sartori (1982), que distingue os

\footnotetext{
2 Peixoto (2010) utiliza essa mesma metodologia na análise dos parceiros preferenciais de 12 partidos nas eleições municipais de 2000 a 2008.
} 
“partidos relevantes", ou seja, aqueles que apresentaram, ao longo do período analisado, poder de barganha na formação de coalizões governativas e oposicionistas na eleição executiva federal, dos micropartidos, que não possuem esse poder.

A discussão está organizada em três seções, além da introdução e da conclusão. Na segunda seção, são apresentados os estudos realizados nas duas agendas de pesquisa acima referidas, o que permite situar melhor a contribuição oferecida neste estudo. $\mathrm{Na}$ terceira, é delineado o quadro mais geral da participação eleitoral dos partidos relevantes e dos micros, distinguindo-se as tendências no comportamento de ambos, ao longo do período. Esse delineamento permite, na quarta seção, uma melhor contextualização da racionalidade das estratégias coligacionistas dos partidos relevantes, tanto nas disputas executivas federal e estadual quanto nas legislativas federais.

\section{AS COLIGAÇÕES NO SISTEMA POLÍTICO BRASILEIRO: ANTIGAS TEORIAS E NOVAS EVIDÊNCIAS SOBREARACIONALIDADE DOS PARTIDOS}

Soares (1964), em seu estudo sobre as coligações realizadas nas eleições de 1950 a 1962, argumenta que o comportamento coligacionista orienta-se por duas racionalidades: a do esforço mínimo (ou economia de esforços) e a da resistência ideológica. A primeira supõe que os partidos fazem alianças visando ganhos eleitorais, e, justamente por isso, esse comportamento denota racionalidade frente às instituições que regulam sua participação eleitoral. A tese da resistência ideológica, por outro lado, supõe a influência das ideologias dos partidos e de seu enraizamento socioeconômico sobre o cálculo coligacionista. Nos testes da tese da economia de esforços, o autor verifica que os partidos, em geral, realizavam diferentes cálculos nas eleições proporcionais e majoritárias, tanto no nível federal quanto no estadual, e que os pequenos partidos, tendo em vista a superação do quociente eleitoral, aliavamse mais que os grandes. A maior recorrência de alianças nas áreas rurais, nas quais os partidos eram vistos como menos ideológicos que nas urbanas, e o menor número de alianças realizadas pelo PTB, que seria o partido mais ideológico do período, são entendidos como evidências da resistência ideológica.

Souza (1983) e Santos (1987) qualificam as teses de Soares (1964) também por referência às eleições do período de 1950 a 1962. Souza, supondo que a força dos partidos é relativa, dada a variação de seu tamanho entre os estados, conclui que as coligações denotavam, "em alguns casos, afinidades ideológicas, noutros, estratégias de expansão partidária e, em todos, estratégias de ganho eleitoral racionalmente elaboradas"
(1983, p. 160). Santos, por outro lado, constata que a motivação ideológica das coligações estava perdendo espaço para um comportamento estratégico e que "todos os partidos ganhavam, embora uns mais do que outros, além de [as coligações] praticamente assegurarem aos pequenos partidos uma representação que de outro modo seria extremamente duvidosa de ser obtida" (SOUZA, 1987, p. 111).

Embora também testando e qualificando as teses de Soares (1964), uma nova agenda de pesquisa foi aberta por Lima Júnior (1983) e Lavareda (1991), também com foco nas eleições do período 1950 -1962. Lima Júnior reafirma a tese da economia de esforços, ressaltando que os partidos, além de buscarem apoio eleitoral por meio das coligações, têm em vista derrotar seu principal adversário. Sua principal contribuição, no entanto, é mostrar a "contextualização" da racionalidade que orientava o cálculo coligacionista. $\mathrm{O}$ pressuposto da análise é a coexistência, no sistema partidário brasileiro, de diferentes subsistemas, no nível federal e em cada um dos estados, caracterizados por diferentes números de partidos e graus de fragmentação. Sendo o tamanho dos partidos diferente em cada subsistema, diz Lima Júnior, “as decisões partidárias de formar alianças ${ }^{3}$ foram racionais porque tinham como principal objetivo maximizar o apoio eleitoral e foram contextuais porque tomadas localmente, à luz dos resultados da eleição prévia, e não de acordo com uma estratégia partidária nacional" (LIMA JÚNIOR, 1983, p. 77).

A principal contribuição de Lavareda (1991) está na mesma direção da de Lima Júnior (1983), mas, em vez de uma racionalidade contextual, haveria um esforço por parte dos partidos em incorporar, nas eleições proporcionais federais, elementos relacionados à disputa majoritária estadual. Verificando que os grandes partidos frequentemente perdiam cadeiras com as alianças, e que os pequenos eram os mais favorecidos nas coligações, Lavareda argumenta que as coligações feitas pelos primeiros nas eleições proporcionais federais " $[. .$.$] funcionavam como instrumento de$ barganha para amealhar apoio de pequenos nas legendas nas eleições de soma zero - os pleitos majoritários de turno único para os executivos estaduais" (LAVAREDA, 1991, p. 115-116). A partir disso, o autor conclui que o papel de articulação do sistema "era cumprido pelas disputas em torno dos governos estaduais. Era esse

\footnotetext{
3 Na literatura referida ao período 1950-1962, é comum a utilização do termo "aliança" como sinônimo de coligação, como chama a atenção Schmitt $(2000 ; 2003)$. Neste estudo, o termo "aliança" denota, como já salientado, pares de partidos em uma mesma coligação.
} 
pleito que, de certa forma, estruturava em cada estado o desenho das demais competições, inclusive as proporcionais" (idem, p. 118).

As agendas de pesquisas abertas por Soares (1964), Lima Júnior (1983) e Lavareda (1991) têm estimulado uma série de estudos sobre as coligações realizadas no período posterior a 1986, que testam, por métodos variados, tanto as teses de esforço mínimo e de resistência ideológica quanto a influência das eleições majoritárias federal e estadual sobre as eleições proporcionais (ou para o poder Legislativo). A inclusão de preocupações correlatas nessas agendas, em especial a questão da proporcionalidade entre votos e representação legislativa dos partidos e a fragmentação do sistema partidário (NICOLAU, 1996; BRAGA, 2006a; 2006b), mostra a importância das coligações na formatação do sistema partidário brasileiro.

$\mathrm{Na}$ agenda de pesquisa aberta por Soares (1964), há menos controvérsia, especialmente quanto à tese de esforço mínimo, com praticamente todos os estudos sobre as coligações realizadas no pós-1986 apontando para o sucesso dessa estratégia em termos de ganhos eleitorais. No que se refere à tese de resistência ideológica, os estudos indicam diluição gradativa de considerações de cunho ideológico na formação das coligações nos níveis federal, estadual ou municipal, mas as conclusões variam quanto à ênfase que colocam nessa diluição. Os estudos de Novaes (1994), Sousa (2005), Dantas (2007), Carreirão e Nascimento (2010), Krause e Godoi (2010) e Leoni (2011) mostram gradativa desconsideração das ideologias, evidenciada pelo crescimento do número de coligações constituídas por partidos de todos os blocos ideológicos, enquanto Schmitt (2000; 2003), Machado (2005), Carreirão (2006) e Mignozzetti, Galdino e Bernabel (2011) apontam a importância, embora residual, de considerações ideológicas no cálculo coligacionista. $\mathrm{O}$ estudo mais abrangente, em termos da empiria utilizada, é o de Carreirão e Nascimento (2010), que foca as eleições para a Câmara, Senado, governadorias e assembleias, no período 1986-2006. Utilizando uma tipologia bastante difundida na literatura (SCHMITT, 2000; 2003; KRAUSE \& GODOI, 2010; MACHADO, 2005; DANTAS, 2007), Carreirão e Nascimento (idem) verificam o crescimento, no período citado, das coligações inconsistentes (entre partidos de direita e de esquerda) para todos os cargos, relativamente às semiconsistentes (entre os partidos de centro com os da direita ou os da esquerda) e às consistentes (entre partidos de um mesmo bloco ideológico).

$\mathrm{Na}$ segunda agenda de pesquisa, também há consensos, mas ainda há questões bastante controversas. A influência dos cálculos realizados nas disputas majoritárias estaduais sobre os que são feitos na formação das coligações para a Câmara são confirmados em diversos estudos, em especial os de Nicolau (1996) e Samuels (2003). Nicolau argumenta que essa influência é explicada pelo "federalismo partidário": sendo a força dos partidos desigualmente distribuída no território, a coligação interessa tanto aos grandes quanto aos pequenos, como mostraram Souza (1983) e Santos (1987) na análise das coligações do período 1950-1962. O efeito dessa vinculação seria, de acordo com o autor, a fragmentação da representação na Câmara e, como argumenta também Lima Júnior (1997), o deslocamento do sistema partidário nacional dos subsistemas estaduais. Nicolau mostra ainda a sofisticação dos cálculos realizados pelos partidos para a escolha de coligações que maximizam o apoio eleitoral nas eleições proporcionais federais: a magnitude do distrito e o tamanho dos partidos atuam de forma negativa em sua decisão, enquanto o tempo a ser usufruído no horário gratuito de propaganda eleitoral, o poder de chantagem dos competidores e o número de candidatos que cada partido pode lançar os estimulariam a coligarem-se.

Samuels (2003) busca demonstrar que, no Brasil, as coligações realizadas nas eleições para a Câmara, em 1994 e 1998, foram influenciadas pelas disputas para as governadorias e não pelas eleições presidenciais. $\mathrm{O}$ autor argumenta que, $(i)$ dada a estrutura de carreira dos deputados brasileiros, na qual os cargos nos executivos estaduais são mais valorizados que a reeleição para o legislativo federal ${ }^{4}$, (ii) em virtude de as lideranças partidárias regionais disponibilizarem mais recursos financeiros e organizacionais para os candidatos aos cargos executivos que para os candidatos aos cargos proporcionais e, por fim, (iii) como resultado da visibilidade eleitoral que a disputa majoritária angaria, é mais provável que, visando à maximização de suas chances de carreira, os deputados alinhem-se ao governador e não ao presidente ${ }^{5}$.

\footnotetext{
4 De acordo com Samuels (2003a), entre 35\% e 40\% dos deputados brasileiros buscam, no final do mandato, cargos extralegislativos, especificamente, cargos nos poderes executivos estaduais e municipais. Entre os que buscam a reeleição, 63,5\% são bem-sucedidos nos períodos democráticos e 75,3\%, nos períodos de ditadura. Além disso, salienta o autor, muitos deputados deixam a Câmara para ocupar cargos na estrutura administrativa federal, estadual e até municipal.

5 Os dois últimos argumentos de Samuels (idem) merecem ressalvas a partir de seus próprios dados. No que se refere à estrutura de carreira, é preciso considerar que os cargos mais buscados são realmente os do poder Executivo, mas nos três níveis de governo e não apenas no estadual. Além disso, a classificação que o autor propõe dos cargos é ambígua. Argumentando que o distrito eleitoral do senador é o estado, ele classifica esse cargo como estadual. O cargo de deputado federal, que também tem os estados como distrito, é classificado, no entanto, como um cargo
} 
Os estudos que buscam avaliar a influência da dinâmica das eleições presidenciais sobre os outros pleitos são também variados quanto à empiria utilizada, métodos de análise e perguntas de pesquisa. Krause (2005), buscando avaliar o grau de nacionalização dos partidos, compara as coligações para os poderes executivos federal e estaduais no período 1994-2002. A autora verifica correlações muito fracas entre ambas, o que, em seu entendimento, indica "dificuldades dos partidos brasileiros de agirem de forma uniforme, e um débil processo de nacionalização das organizações" (idem, p. 135). Braga (2006a; 2006b), por seu turno, analisa as votações e coligações para a Câmara e Senado, de 1990 a 2002, e conclui que há “um processo de articulação envolvendo as lideranças nacionais e estaduais para manter congruência nas coligações partidárias, de modo a aumentar as chances de êxito na eleição em nível nacional" (idem, p. 281282).

Outros estudos têm buscado avaliar a influência da racionalidade da disputa majoritária federal e estadual sobre os pleitos municipais. A falta de consenso aqui é semelhante à encontrada nas análises sobre as coligações para o Congresso. Dantas (2007), por exemplo, argumenta que a influência predominante é a das disputas executivas estaduais, enquanto Machado e Miguel (2008) e Ribeiro (2005) apontam a importância da bipolarização na disputa presidencial sobre coligações municipais.

Assim, no que se refere à influência da racionalidade das estratégias coligacionistas das eleições majoritárias (federal e estadual) sobre os cálculos que orientam as coligações para outros cargos, não há uma posição única na literatura. A esse respeito cabe fazer uma ponderação importante: a legislação que regulamentou as eleições de 1986 a 1998, como já mencionado, proibia que os partidos realizassem, nas disputas para a Câmara, coligações incongruentes em relação às firmadas para as governadorias. Assim, entre $1986 \mathrm{e}$ 1998, a congruência entre as coligações majoritárias

federal. Por fim, ainda conforme os dados apresentados, a maioria dos cargos buscados pelos deputados, no nível estadual, é na estrutura organizacional partidária, o que diminui a influência dos governadores na estrutura de carreira dos deputados. O argumento que parece justificar o procedimento é o de que os governadores são líderes partidários regionais. Pressupondo a veracidade da afirmação, não se pode dizer, no entanto, que os líderes partidários regionais são ou foram governadores. No que se refere aos recursos que os deputados usufruem pelo alinhamento à campanha do governador, cabe considerar que são recursos partidários e não do candidato a governador. Assim, os dados permitem também inferir que a deferência dos políticos deve ser prestada à organização partidária estadual e não aos governadores. estaduais e as proporcionais federais não surpreende $\mathrm{e}$ prescinde de outros fatores para sua explicação que não a própria legislação em vigor. Prescinde também de maiores análises a não incongruência entre coligações presidenciais e as coligações para os outros pleitos, federais e estaduais, nas eleições de 2002 e 2006, posto que esta foi a exigência colocada pela verticalização.

A partir disso, há que se considerar que os mesmos incentivos atribuídos à eleição majoritária estadual também podem ser atribuídos à majoritária federal. Entre os incentivos institucionais, destacam-se a exigência de verticalização em 2002 e 2006 e a simultaneidade dos pleitos executivos e legislativos nos níveis federal e estadual, a partir de 1994. Há também fortes incentivos políticos para a vinculação das estratégias coligacionistas configuradas na eleição legislativa federal às estabelecidas na eleição presidencial como, por exemplo, $(i)$ a visibilidade que a disputa majoritária federal angaria, como chamam a atenção Shugart e Carey (1992) e Samuels (2003), por referência à disputa majoritária estadual e (ii) a centralização, no poder Executivo, de recursos políticos importantes para a sobrevivência política dos parlamentares, como as prerrogativas legislativas do Presidente da República, que lhe permitem influenciar o ritmo e o conteúdo da produção legislativa, e a de execução discricionária de emendas orçamentárias (FIGUEIREDO \& LIMONGI, 1999; 2008).

$\mathrm{Na}$ análise a seguir, busca-se verificar se esses incentivos são traduzidos no padrão de preferências e resistências das estratégias coligacionistas dos partidos e o grau de aproximação dessa resistência com a tradicional resistência ideológica, nas eleições para os cargos legislativos federais e majoritários estaduais. $\mathrm{Na}$ tentativa de contextualizar melhor essas racionalidades, são delineadas, na próxima seção, as tendências mais gerais da participação nas eleições para a Câmara, Senado e governadorias, entre 1990 e 2010.

\section{AS TENDÊNCIAS NA PARTICIPAÇÃO ELEITORAL DOS PARTIDOS RELEVANTES E DOS MICROS.}

Dada a significativa fragmentação do sistema partidário brasileiro, a avaliação da influência da racionalidade que orienta a formação das coligações executivas federais sobre as estratégias coligacionistas nas eleições legislativas federais e majoritárias estaduais ganha em parcimônia e acuidade se focada nos partidos que têm, na competição majoritária federal, poder de barganha na formação de coalizões governativas e oposicionistas, podendo, por isso, ser denominados "partidos relevantes", nos termos de Sartori (1982). Considerando a trajetória dos partidos na disputa presi- 
dencial no período posterior a 1989, descrita detalhadamente na quarta seção, onze partidos foram classificados como relevantes, sendo o restante considerado como micros. Os relevantes são: PT, PC do B, PSB, PDT e PCB/PPS, à esquerda do espectro ideológico; PSDB e PMDB, ao centro; PL/PR, PTB, PDS/PPR/
PPB/PP (doravante PDS-PP) e PFL/DEM à direita.

Na Tabela 1, é apresentado o número de partidos relevantes e micros que participaram das eleições, para a Câmara, Senado e governadorias no período 19902010.

TABELA 1 - PARTIDOS QUE PARTICIPARAM DAS ELEIÇÕES (1990-2010), POR TIPO E CASA(N)

\begin{tabular}{|l|l|c|c|c|c|c|c|}
\hline \multirow{2}{*}{ Casa } & \multirow{2}{*}{ Tipo de Partido } & \multicolumn{5}{c|}{ Eleições } \\
\cline { 3 - 8 } & & $\mathbf{1 9 9 0}$ & $\mathbf{1 9 9 4}$ & $\mathbf{1 9 9 8}$ & $\mathbf{2 0 0 2}$ & $\mathbf{2 0 0 6}$ & $\mathbf{2 0 1 0}$ \\
\hline Câmara dos Deputados & Micros & 22 & 12 & 19 & 19 & 18 & 16 \\
& Relevantes & 11 & 11 & 11 & 11 & 11 & 11 \\
& Total & 33 & 23 & 30 & 30 & 29 & 27 \\
\hline Senado Federal & Micros & 18 & 8 & 19 & 19 & 18 & 16 \\
& Relevantes & 11 & 11 & 11 & 11 & 11 & 11 \\
& Total & 29 & 19 & 30 & 30 & 29 & 27 \\
\hline Governadorias & Micros & 13 & 8 & 15 & 14 & 17 & 16 \\
& Relevantes & 10 & 9 & 10 & 10 & 11 & 11 \\
& Total & 13 & 17 & 25 & 24 & 29 & 27 \\
\hline
\end{tabular}

FONTE: A autora, a partir de dados do Tribunal Superior Eleitoral (TSE), Schmitt (2000), Carreirão (2006) e Nicolau (2006).

Todos os 11 partidos considerados relevantes, como é mostrado na Tabela 1, participaram, coligados ou isoladamente, de todas as eleições para a Câmara e o Senado, assim como, em 2006 e 2010, das disputas para as governadorias. Nestas, de 1990 a 2002, a participação desses partidos foi mais restrita ${ }^{6}$. Quanto aos micropartidos, observa-se que sua participação foi mais restrita nas primeiras eleições para as governadorias e para o Senado. Em 2006 e 2010, no entanto, também esses partidos participaram igualmente das eleições para os três cargos.
As mudanças na legislação eleitoral (congruência com as disputas majoritárias estaduais e verticalização a partir da eleição presidencial) influenciaram bastante as estratégias coligacionistas dos dois tipos de partidos. Na Tabela 2, é apresentado o total de coligações realizadas nas eleições para a Câmara, Senado e governadorias, de 1990 a 2010, distinguindo-se o número das que foram constituídas por pelo menos um dos partidos relevantes daquelas compostas apenas por micros.

TABELA 2 - COLIGAÇÕES (TOTAL) E POR TIPO DE PARTIDO INTEGRANTE, CASA E ELEIÇÃO (1990-2010) (N).

\begin{tabular}{|c|c|c|c|c|c|c|}
\hline \multirow{2}{*}{ Casa } & \multicolumn{6}{|c|}{ Eleição } \\
\hline & 1990 & 1994 & 1998 & 2002 & 2006 & 2010 \\
\hline \multicolumn{7}{|c|}{ Coligações (total) } \\
\hline Câmara dos Deputados & 95 & 113 & 104 & 139 & 144 & 105 \\
\hline Senado Federal & 92 & 71 & 74 & 112 & 87 & 79 \\
\hline Governadorias & 82 & 78 & 83 & 106 & 105 & 78 \\
\hline \multicolumn{7}{|c|}{ Coligações com pelo menos um dos partidos relevantes } \\
\hline Câmara dos Deputados & 86 & 103 & 87 & 122 & 93 & 88 \\
\hline Senado Federal & 86 & 67 & 66 & 105 & 67 & 73 \\
\hline Governadorias & 79 & 73 & 76 & 99 & 76 & 71 \\
\hline \multicolumn{7}{|c|}{ Coligações apenas entre micros } \\
\hline Câmara dos Deputados & 9 & 10 & 17 & 17 & 51 & 17 \\
\hline Senado Federal & 8 & 4 & 8 & 7 & 20 & 6 \\
\hline Governadorias & 3 & 5 & 7 & 7 & 29 & 7 \\
\hline
\end{tabular}

FONTE: A autora, a partir de dados do Tribunal Superior Eleitoral (TSE), Schmitt (2000), Carreirão (2006) e Nicolau (2006).

6 O PC do B não participou de 1994 a 2002, o PCB/PPS em 1990 e 1994 e o PL/PR, em 1998. 
$\mathrm{Na}$ avaliação dos dados Tabela 2, constata-se significativa variação do número de "Coligações (total)" entre os cargos e, no mesmo cargo, entre as eleições. Nas eleições para a Câmara, a distribuição apresenta crescimento significativo em 1994, 2002 e 2006. Observa-se que, em 1994 e 2002, o aumento está relacionado com o comportamento dos partidos relevantes, como mostra a sequência do número de "Coligações com pelo menos um dos partidos relevantes", sendo que, em 1994, o aumento está relacionado com a preferência desses partidos pela coligação, em relação à eleição de 1990, mas mantendo coerência ideológica em suas escolhas, como será mostrado à frente. Em 2002, por outro lado, o aumento do número de coligações foi estimulado pela exigência inesperada de verticalização e ocorreu também nas eleições para o Senado e governadorias, o que corrobora as análises de Fleischer (2010) e Marchetti (2010) sobre os amplos efeitos dessa exigência. Em 2006, o aumento do número de coligações resultou do comportamento dos micros, o que pode ser verificado na sequência do número de "Coligações apenas entre micros". Provavelmente esse crescimento foi influenciado também pela exigência de verticalização ${ }^{7}$, mas ele deve-se, principalmente, à estratégia de apresentação de um número expressivamente maior de candidatos aos governos estaduais naquela ocasião ${ }^{8}$.

O fato de a verticalização ter influenciado o número de coligações em 2002, mas não em 2006, tem uma explicação plausível. Em 2002, a exigência do TSE foi feita depois de terem sido formadas as coligações presidenciais, às quais eles foram obrigados a replicar nas disputas para os outros cargos. Em 2006, no entanto, os partidos já compuseram as coligações presidenciais sabendo que não poderiam coligar-se, nos outros pleitos, com os integrantes de coligações adversárias, isto é, tiveram relativa liberdade para estabelecer, previamente, arranjos mais condizentes com seus interesses nas diversas arenas.

Se as "eleições desviantes" forem desconsideradas - as realizadas pelos partidos relevantes para a Câmara, em 1994 e 2002, para o Senado e governadorias, em 2002, e as realizadas pelos micros para Câmara, Senado e governadorias, em 2006 - percebe-se significativa estabilidade no número de coligações formadas pelos dois tipos de partidos. Entre os partidos relevantes, a média de coligações para a Câmara é de 89; para o Senado, 72; para as governadorias, 75 , sendo o desvio padrão de 3,1, para a Câmara e governadorias, e de 8,4 para o Senado. A maior variação no número de coligações para o Senado justifica-se pela variação do número de cadeiras em disputa $(1 / 3$ e $2 / 3$, alternadamente). Entre micros, a média de coligações para a Câmara é de 14 (desvio padrão de 4,1) e, para o Senado e governadorias, de seis e oito coligações (desvio padrão de 1,7 e 1,8, respectivamente).

É interessante notar que a estabilidade no número de coligações é simultânea ao significativo aumento, de eleição para eleição, do número de participações eleitorais dos dois tipos de partido. Na Tabela 3, é apresentado o número de participações dos micropartidos, na disputa para os três cargos, distinguindo-se a participação isolada da participação em coligação.

TABELA 3 - PARTICIPAÇÃO ELEITORAL DOS MICROPARTIDOS POR CASA, MODALIDADE E ELEIÇÃO (1990-2010) $(\%)$

\begin{tabular}{|c|c|c|c|c|c|c|c|c|c|}
\hline \multirow[b]{2}{*}{ Casa } & \multirow[b]{2}{*}{ Modalidade } & \multicolumn{6}{|c|}{ Eleição } & \multirow[b]{2}{*}{ Média } & \multirow{2}{*}{$\begin{array}{l}\text { Desvio } \\
\text { Padrão }\end{array}$} \\
\hline & & 1990 & 1994 & 1998 & 2002 & 2006 & 2010 & & \\
\hline \multirow[t]{3}{*}{ Câmara } & Em coligação & 62,8 & 51,3 & 78,4 & 82,4 & 79,5 & 73,1 & 71,3 & \multirow{2}{*}{10,9} \\
\hline & Isoladamente & 37,2 & 48,7 & 21,6 & 17,6 & 20,5 & 26,9 & 28,8 & \\
\hline & $(\mathrm{N})$ & (274) & (351) & (352) & (431) & $(430)$ & (379) & (369) & 53,7 \\
\hline \multirow[t]{3}{*}{ Senado } & Em coligação & 86,4 & 70,1 & 79,4 & 78,8 & 73,4 & 81,2 & 78,1 & \multirow{2}{*}{5,2} \\
\hline & Isoladamente & 14,1 & 29,9 & 20,6 & 21,2 & 26,6 & 18,8 & 21,9 & \\
\hline & $(\mathrm{N})$ & (156) & (134) & (301) & (345) & (338) & (329) & (267) & 220,1 \\
\hline \multirow[t]{3}{*}{ Governadorias } & Em coligação & 84,8 & 78,5 & 82,5 & 80,5 & 77,9 & 82,9 & 81,2 & \multirow{2}{*}{2,5} \\
\hline & Isoladamente & 15,2 & 21,5 & 17,5 & 19,5 & 22,1 & 17,1 & 18,8 & \\
\hline & $(\mathrm{N})$ & (151) & (149) & (325) & (353) & (344) & (410) & (289) & 101,4 \\
\hline
\end{tabular}

FONTE: A autora, a partir de dados do Tribunal Superior Eleitoral (TSE), Schmitt (2000), Carreirão (2006) e Nicolau (2006).

\footnotetext{
7 Em 2006, quatro micropartidos (PSOL, PRP, PSDC e PSL), dois a mais que em 2002, apresentaram candidatos presidenciais e, por isso, ficaram restringidos em suas coligações.
}

8 O número de candidatos a governador apresentados pelos micros cresceu significativamente ao longo do período, mas, em 2006, o salto foi expressivo. O número de candidatos em 1990, 
A primeira observação a ser feita, a partir dos dados da Tabela 3, relaciona-se ao significativo crescimento da participação absoluta dos micropartidos ao longo do período, indicando sua dispersão no território nacional: de 1990 a 2010, nas eleições para a Câmara, o número de participações passou de 274 para 379; para o Senado, de 156 para 329; para as governadorias, de 151 para 410. Em termos percentuais, o aumento da participação foi, nas eleições para a Câmara, Senado e governadorias, de $38,3 \%, 110,9 \%$ e $171,5 \%$, respectivamente. As eleições de que os micros mais participam são para a Câmara. Em termos percentuais, a participação nas eleições para essa Casa é 38,2\% e $27,7 \%$ maior que naquelas para o Senado e governadorias, respectivamente.

Os partidos relevantes apresentam também tendência consistente de aumento do número de participações eleitorais, especialmente em coligação, conforme os dados da Tabela 4, que distingue a participação por modalidade, Casa e eleição.

TABELA 4 - PARTICIPAÇÃO ELEITORAL DOS PARTIDOS RELEVANTES POR MODALIDADE, CASA E ELEIÇÃO $(1990-2010)(\%)$

\begin{tabular}{|c|c|c|c|c|c|c|c|c|c|}
\hline \multirow{2}{*}{ Casa } & \multirow{2}{*}{ Modalidade } & \multicolumn{6}{|c|}{ Eleição } & \multirow{2}{*}{ Média } & \multirow{2}{*}{$\begin{array}{l}\text { Desvio } \\
\text { Padrãc }\end{array}$} \\
\hline & & 1990 & 1994 & 1998 & 2002 & 2006 & 2010 & & \\
\hline \multirow[t]{4}{*}{ Câmara } & Em coligação & 70,7 & 88,2 & 84,5 & 77,0 & 82,8 & 90,2 & 82,2 & 7,3 \\
\hline & $\begin{array}{l}\text { Em coligação apenas } \\
\text { com micros }\end{array}$ & 3,5 & 6,8 & 4,8 & 11,8 & 5,4 & 4,7 & 6,2 & 3 \\
\hline & Isoladamente & 25,8 & 5,1 & 10,7 & 11,1 & 11,8 & 5,1 & 11,6 & 7,6 \\
\hline & Total $(\mathrm{N})$ & (283) & (296) & (291) & (296) & (297) & (295) & (293) & 5,3 \\
\hline \multirow[t]{4}{*}{ Senado } & Em coligação & 87,7 & 69,7 & 87,0 & 75,5 & 88,6 & 96,5 & 84,2 & 9,8 \\
\hline & $\begin{array}{l}\text { Em coligação apenas } \\
\text { com micros }\end{array}$ & 3,7 & 5,6 & 2,0 & 9,6 & 1,6 & 2,1 & 4,1 & 3,1 \\
\hline & Isoladamente & 8,6 & 24,8 & 11,0 & 14,9 & 9,8 & 1,4 & 11,8 & 7,8 \\
\hline & Total $(\mathrm{N})$ & (268) & (234) & $(254)$ & $(282)$ & (255) & (283) & (263) & 18,8 \\
\hline \multirow[t]{4}{*}{ Governadorias } & Em coligação & 88,0 & 83,5 & 95,7 & 84,8 & 92,6 & 98,2 & 90,5 & 6 \\
\hline & $\begin{array}{l}\text { Em coligação apenas } \\
\text { com micros }\end{array}$ & 1,7 & 6,4 & 1,4 & 7,8 & 1,9 & 1,1 & 3,4 & 2,9 \\
\hline & Isoladamente & 10,3 & 10,2 & 2,8 & 7,4 & 5,6 & 0,7 & 6,2 & 3,9 \\
\hline & Total $(\mathrm{N})$ & (233) & (236) & (282) & $(256)$ & (269) & (283) & $(260)$ & 22 \\
\hline
\end{tabular}

FONTE: A autora, a partir de dados do Tribunal Superior Eleitoral (TSE), Schmitt (2000), Carreirão (2006) e Nicolau (2006).

Na avaliação dos dados da Tabela 4, verifica-se, em primeiro lugar, o aumento da participação eleitoral dos partidos relevantes. Como ocorreu entre os micros, também os partidos relevantes aumentaram sua dispersão no território nacional. Nas eleições para a Câmara, Senado e governadorias, em 1990, esses partidos disputaram as eleições em 95,3\%, 90,2\% e $78,5 \%$ dos 297 distritos eleitorais possíveis 9 , respectivamente; em 2010, sua participação aumentou

1994, 1998, 2002, 2006 e 2010, foi de, respectivamente, 38, 43, $66,80,106$ e 80 . Cabe salientar que o aumento no número de candidatos de 2006 foi provocado especialmente pelo PSOL e o PSDC, que apresentaram candidatos em praticamente todas as unidades da federação.

${ }^{9}$ Número alcançado pela multiplicação de 11 (partidos relevantes) por 27 (distritos eleitorais). para 99,3\%, 95,3\% e 95,3\%, também respectivamente.

Em segundo lugar, verifica-se a forte preferência desses partidos pela coligação, que é maior nas disputas para os cargos majoritários (especialmente as governadorias) que na disputa proporcional. Somando-se os percentuais de participação em coligação ("Em coligação" e "Em coligação apenas com micros"), constatase que $88 \%$ e $94 \%$ das participações, nas eleições legislativas e nas eleições governatoriais, respectivamente, foram em coligação.

Em terceiro lugar, os dados revelam, entre os partidos relevantes, um comportamento inverso ao verificado entre os micros: nas eleições de 2002, houve queda significativa da participação desses partidos em coligação com seus pares, nas disputas para os três cargos, aumentando, correlativamente, o percentual de participação em coligação apenas com micros ou isolada- 
mente.

Embora seja plausível esperar uma diminuição da participação eleitoral dos partidos relevantes em coligação entre si, quando estão em disputa dois terços das cadeiras, os dados mostram que isso não ocorre. A soma da participação percentual nas duas últimas modalidades ("Em coligação apenas com micros" e "Isoladamente") é de 12,3\%, 30,4\%, 13,0\%, 24,5\%, 11,4\% e 3,5\%, em 1990, 1994, 1998, 2002, 2006 e 2010, respectivamente. Assim, em 1994, 2002, quando foram renovados dois terços do Senado, a variação está no sentido esperado (aumento em relação à eleição anterior), mas, em 2010, em sentido inverso.

Por fim, os dados mostram o aumento da preferência dos partidos relevantes pela participação eleitoral em coligação ao longo do período e para os três cargos: nas eleições para o Senado, Câmara e governadorias, esse aumento foi de $23,4 \%, 20,7 \%$ e $9,6 \%$, respectivamente. Cabe chamar a atenção para o fato de que esse aumento, assim como aquele verificado entre os micros, ocorreu em um contexto de marcada estabilidade no número de coligações, como visto na Tabela 2. Isso só foi possível pelo aumento significativo do tamanho das coligações, isto é, do número de alianças entre os partidos em uma mesma coligação. A contraface desse fenômeno foi a diminuição da resistência ideológica, que ocorreu simultaneamente ao surgimento de uma novo tipo de resistência entre os partidos: a política, tratada na próxima seção.

\section{A INFLUÊNCIA DA DINÂMICA MAJORITÁRIA FEDERAL SOBRE AS RESISTENNCIAS E PREFERENCIAS ENTRE OS PARTIDOS RELEVANTES}

O aumento do número de alianças entre os partidos relevantes, em uma mesma coligação, levou a uma ultrapassagem generalizada das fronteiras dos blocos ideológicos, denotando diluição da resistência ideológica no cálculo coligacionista. Mas essa diluição foi simultânea ao surgimento de um novo tipo de resistência: a política, resultante da bipolarização que emergiu na disputa presidencial a partir de 1994.

A bipolarização da competição pelo cargo presidencial, já salientada na literatura, resultou da emergência do PT e do PSDB como os principais competidores: os candidatos apresentados por esses partidos passaram a reunir, já no primeiro turno das eleições, entre 1994 e 2010, em média 81,1\% dos votos, o que denota, de acordo com Miranda (2009), eficiência das eleições presidenciais, nos termos de Shugart e Carey (1992). Em sua trajetória no sistema partidário federal, esses partidos de vocação presidencial, como diz a autora, deslocaram outros partidos competitivos e reuniram em torno de si aliados leais: o PC do B e o PSB, junto com o PT, e o PFL/ DEM, junto com o PSDB.

A influência da bipolarização que emergiu no âmbito da disputa pelo cargo presidencial sobre as coligações ou alinhamentos para os outros pleitos tem sido apontada na literatura referida às coligações eleitorais, destacadamente nos trabalhos de Braga (2006a; 2006b), Carreirão e Nascimento (2010) e Melo (2006; 2010). O ponto importante, a ser verificado aqui, é se essa influência é independente da exigência de verticalização, que forçou a replicação da bipolarização na disputa presidencial nas eleições para os outros cargos federais e estaduais, o que denotaria a natureza política, e não apenas institucional, dos incentivos que a sustentam.

Além da quantidade de votos, a centralidade assumida pelo PT e PSDB na disputa presidencial, em relação aos outros partidos, pode ser avaliada a partir de sua posição na composição das coligações eleitorais. A Tabela 5 traz a posição dos partidos relevantes em todas as coligações presidenciais do atual período democrático, se apresentando candidato ou se parceiro de coligação.

TABELA 5 - PARTICIPAÇÃO DOS PARTIDOS RELEVANTES NAS ELEIÇÕES PRESIDENCIAIS, POR POSIÇÃO NA COLIGAÇÃO (1989-2010) (N)

\begin{tabular}{|l|c|c|c|}
\hline Partido & $\begin{array}{c}\text { Apresentando } \\
\text { Candidato }\end{array}$ & $\begin{array}{c}\text { Parceiro de } \\
\text { Coligação }\end{array}$ & Total \\
\hline PSDB & 6 & - & 6 \\
PT & 6 & - & 6 \\
PDT & 3 & 3 & 6 \\
PC do B & - & 6 & 6 \\
PCB/PPS & 3 & 2 & 5 \\
PSB & 1 & 4 & 5 \\
PTB & 1 & 4 & 5 \\
PFL/DEM & 1 & 3 & 4 \\
PMDB & 2 & 2 & 4 \\
PDS-PP & 2 & 1 & 3 \\
PL/PR & 1 & 2 & 3 \\
\hline
\end{tabular}

FONTE: A autora, a partir de dados do Tribunal Superior Eleitoral (TSE), Schmitt (2000), Carreirão (2006) e Nicolau (2006).

A posição dominante do PT e do PSDB na apresentação de candidatos, como mostrado na Tabela 5 , não deixa dúvidas quanto à sua posição no sistema partidário federal, especialmente porque eles angariaram, já no primeiro turno da disputa presidencial, mais de $80 \%$ da votação. Nessa trajetória de 20 anos, eles deslocaram outros competidores importantes, como o PDT e PCB/PPS, que apresentaram candidatos em três eleições, assim como o PMDB e o PDS-PP, que disputaram apenas as duas 
primeiras eleições do período. Esses quatro partidos, em especial, terminaram deslocando suas ambições para outras arenas, a estadual ou apenas a congressual, nas quais reúnem os recursos que sustentam seu poder de barganha na composição das coalizões governativas federais. De fato, em 2010, além do PT e do PSDB, apenas micropartidos arriscaram-se na competição pelo cargo presidencial.

Como parceiros de coligações presidenciais, destacaram-se, ao longo do período, o PC do B, PSB, PTB, PFL/DEM e PDT, mas há importantes variações entre eles, no que se refere ao grau de consistência do alinhamento. O PC do B e o PSB têm demonstrado apoio reiterado aos candidatos petistas em seis e quatro eleições, respectivamente, assim como o PFL/DEM tem demonstrado apoio constante ao PSDB. O PDT e o PTB também têm sido parceiros de coligação presidencial, mas oscilaram seu apoio. No caso do PDT, a oscilação foi entre o PT e o PPS; no caso do PTB, entre o PT e o PSDB.

Assim, PT, PC do B e, em menor medida, o PSB, à esquerda, e PSDB e PFL/DEM, ao centro-direita, têm constituído o "núcleo duro" das seis últimas coligações presidenciais, bem como, no Congresso, o das coalizões de apoio e oposição ao governo. Esses partidos, diferentemente do PMDB, PDT, PTB, PL/PR, PDSPP e PPS, têm replicado, sob a forma de resistência política na constituição das coligações, a mesma bipolarização que imprimiram na disputa presidencial.

Antes de tratar dessa resistência política, vejamos o padrão aliancista mais geral dos partidos relevantes, dentro do qual ela adquire sentido. Na Tabela 6, é apresentado o número de alianças realizadas no período, por Casa e eleição.

TABELA6 -ALIANÇAS ENTRE PARTIDOS RELEVANTES, POR CASA E ELEIÇÃO (1990-2010) (N)

\begin{tabular}{|c|c|c|c|c|c|c|c|}
\hline \multirow{2}{*}{ Casa } & \multicolumn{6}{|c|}{ Eleição } & \multirow{2}{*}{ Total } \\
\hline & 1990 & 1994 & 1998 & 2002 & 2006 & 2010 & \\
\hline Câmara dos Deputados & 240 & 329 & 362 & 202 & 314 & 397 & 1844 \\
\hline Senado Federal & 301 & 197 & 350 & 200 & 344 & 507 & 1899 \\
\hline Governadorias & 291 & 283 & 449 & 202 & 379 & 530 & 2134 \\
\hline
\end{tabular}

FONTE: A autora, a partir de dados do Tribunal Superior Eleitoral (TSE), Schmitt (2000), Carreirão (2006) e Nicolau (2006).

A primeira observação, relativa à Tabela 6 , referese ao aumento significativo, entre 1990 e 2010 , do número de alianças entre os partidos relevantes: $65,4 \%$, $68,4 \%$ e $82,1 \%$, nas eleições para a Câmara, Senado e governadorias, respectivamente. Em segundo lugar, observa-se que a exigência de verticalização, em 2002 e 2006, levou a uma diminuição significativa do número de alianças entre esses partidos, especialmente em 2002, pois, como já mencionado, naquela ocasião, os partidos não previram a regra e fizeram coligações amplas para a disputa presidencial. Em 2006, conhecendo previamente as regras, eles restringiram ao mínimo o número de parceiros na coligação presidencial, o que lhes permitiria fazer combinações variadas nas disputas para os outros cargos, seguindo, assim, a tendência do período. Em terceiro lugar, observa-se que a preferência dos partidos relevantes em aliar-se é maior nas eleições para as governadorias. Congruente com o maior número de coligações nas disputas para as governadorias, visto na Tabela 2 , também o número de alianças feitas pelos partidos relevantes nas disputas desse cargo é maior que nas eleições para o Senado e para a Câmara (234 e 290 alianças a mais, respectivamente) 10 .

Os dados da Tabela 7 permitem uma melhor aproximação das preferências e resistências no comportamento aliancista. Eles se referem ao número de alianças estabelecidas pelos partidos relevantes, entre si, nas seis eleições para a Câmara, Senado e governadorias.

\footnotetext{
10 Nas Tabelas 1, 2 e 3, no Anexo, apresenta-se o número de alianças por partido, eleição e cargo. Observa-se que, nesse cálculo, o número de alianças fica duplicado, pois, como na Tabela 7, uma mesma aliança é somada no cômputo dos dois partidos que a constituem.
} 
TABELA 7 -ALIANÇAS ENTRE OS PARTIDOS RELEVANTES, POR CASA E ELEIÇÃO (1990-2010) (N)

\begin{tabular}{|c|c|c|c|c|c|c|c|c|c|c|}
\hline Partido & PCdoB & PSB & PDT & PCB/PPS & PSDB & PMDB & PL/PR & PTB & PDS-PP & PFL/DEM \\
\hline \multicolumn{11}{|c|}{ Câmara dos Deputados } \\
\hline PT & 117 & 75 & 33 & 34 & 7 & 17 & 42 & 13 & 12 & 1 \\
\hline PCdoB & & 71 & 44 & 43 & 10 & 23 & 46 & 17 & 11 & 6 \\
\hline PSB & & & 43 & 42 & 18 & 16 & 23 & 17 & 20 & 6 \\
\hline PDT & & & & 48 & 25 & 21 & 20 & 42 & 20 & 14 \\
\hline PCB /PPS & & & & & 45 & 25 & 17 & 29 & 23 & 35 \\
\hline PSDB & & & & & & 51 & 32 & 30 & 37 & 65 \\
\hline PMDB & & & & & & & 37 & 27 & 36 & 43 \\
\hline PL/PR & & & & & & & & 45 & 44 & 47 \\
\hline PTB & & & & & & & & & 53 & 58 \\
\hline PDS-PP & & & & & & & & & & 68 \\
\hline \multicolumn{11}{|c|}{ Senado Federal } \\
\hline PT & 118 & 77 & 37 & 36 & 6 & 20 & 44 & 15 & 15 & 1 \\
\hline PCdoB & & 71 & 50 & 41 & 17 & 27 & 44 & 15 & 15 & 5 \\
\hline PSB & & & 43 & 44 & 24 & 19 & 29 & 25 & 23 & 11 \\
\hline PDT & & & & 45 & 23 & 21 & 19 & 35 & 25 & 10 \\
\hline PCB/PPS & & & & & 45 & 26 & 18 & 36 & 25 & 38 \\
\hline PSDB & & & & & & 46 & 33 & 37 & 36 & 63 \\
\hline PMDB & & & & & & & 39 & 26 & 38 & 41 \\
\hline PL/PR & & & & & & & & 44 & 45 & 42 \\
\hline PTB & & & & & & & & & 53 & 56 \\
\hline PDS-PP & & & & & & & & & & 62 \\
\hline \multicolumn{11}{|c|}{ Governadorias } \\
\hline PT & 123 & 79 & 41 & 40 & 7 & 22 & 43 & 17 & 16 & 2 \\
\hline PCdoB & & 76 & 54 & 42 & 17 & 32 & 48 & 19 & 16 & 6 \\
\hline PSB & & & 46 & 49 & 24 & 22 & 30 & 27 & 26 & 11 \\
\hline PDT & & & & 46 & 27 & 26 & 23 & 39 & 30 & 15 \\
\hline PCB/PPS & & & & & 52 & 34 & 25 & 41 & 28 & 41 \\
\hline PSDB & & & & & & 53 & 36 & 42 & 43 & 71 \\
\hline PMDB & & & & & & & 52 & 36 & 32 & 47 \\
\hline PL/PR & & & & & & & & 54 & 54 & 52 \\
\hline PTB & & & & & & & & & 61 & 68 \\
\hline PDS-PP & & & & & & & & & & 71 \\
\hline
\end{tabular}

FONTE: A autora, a partir de dados do Tribunal Superior Eleitoral (TSE), Schmitt (2000), Carreirão (2006) e Nicolau (2006).

Os dados da Tabela 7 permitem comparar, em primeiro lugar, o número de alianças realizadas no período, por partido e cargo. Todos os partidos fizeram mais alianças para as governadorias que para a Câmara e o Senado, como já salientado, mas há variações. Comparando o número de alianças para as governadorias e a Câmara, verifica-se que os partidos que apresentam maior variação foram o PTB, PL/PR e PMDB (respectivamente, 73, 64 e 60 alianças a mais para as governadorias); a menor variação é apresentada pelo PDT, PT e PFL (respectivamente, 37, 39 e 41 alianças a mais). Entre as governadorias e o Senado, a maior variação é também do PTB, PL/PR e PFL (62, 60 e 55 alianças a mais para as governadorias, respectivamente); a menor variação é apresentada também pelo PT, PSB e PC do B (21, 24 e 30 alianças, respectivamente). Maior semelhança no padrão aliancista dos partidos relevantes é encontrada entre a Câmara e o Senado. Nessa comparação, encontramos menores variações no número de alianças feitas pelo PDT, PL/PR e PMDB (diferenças de 2, 4 e 7 alianças, respectivamente); as maiores variações são apresentadas pelo PSB, PT e PC do B $(35,18$ e 15 alianças, respectivamente).

No entanto, essa análise, que compara diferenças entre dados agregados, esconde variações no comportamento aliancista dos partidos em cada eleição. O cálculo do coeficiente de correlação na distribuição do número de alianças de cada partido permite uma análise mais qualificada do grau de coerência mantido 
por cada um deles no estabelecimento de alianças para os diferentes cargos em um mesmo ano eleitoral. Entre a distribuição do número de alianças feitas para as governadorias e a Câmara, há alta correlação $(r=1,0)$ no número de alianças feitas pelo $\mathrm{PT}, \mathrm{PC}$ do $\mathrm{B}, \mathrm{PSB}$ e PFL/DEM, nas seis eleições aqui consideradas; as menores correlações são apresentadas pelo PDS-PP $(r=0,7$ e $r=0,5$, em 1990 e 2010), PSDB ( $r=0,7$, em 1994) e PMDB ( $r=0,6$, em 2006). Esses três partidos, assim como os não citados, apresentam coeficientes entre $r=1$ e $r=0,8$, na distribuição das alianças nas outras eleições para as governadorias e a Câmara.

Nas disputas para as governadorias e o Senado, a correlação é ainda maior: quase todos os partidos apresentam coeficientes $r=1,0$ ou $r=0,9$; apenas o PMDB e o PDS/PP apresentam coeficientes menores (o primeiro, $\mathrm{r}=0$,4, em 2006; o segundo, $\mathrm{r}=0,6$ e $\mathrm{r}=$ 0,8, em 1994 e 2006). Assim, o padrão aliancista dos partidos relevantes para as governadorias é mais similar ao do Senado que ao da Câmara, embora haja exceções importantes.

No padrão aliancista para a Câmara e o Senado, há também altos coeficientes de correlação, além de variação bem menor que a verificada entre governadorias e Congresso: praticamente todos os partidos apresentam coeficientes no valor de $r=1,0$ a $r=0,8$. As exceções ficam por conta do PDS-PP $(r=$ 0,5 em 2010) e do PSDB ( $r=0,7$, em 1998).

Ressalva importante deve ser feita com relação aos partidos de vocação presidencial - PT e PSDB - e seus principais aliados: PC do B, PSB e PFL, que apresentaram coeficientes de correlação altos $(\mathrm{r}=1)$ em todas as eleições do período e entre todos os cargos. O PSDB apresenta valores menores, como visto anteriormente, mas, nas eleições posteriores a 1998, também apresenta coeficientes altos. Certamente, esse achado denota um esforço bem maior desses partidos, no sentido de coordenar suas estratégias coligacionistas entre os diversos pleitos e distritos eleitorais, o que relativiza o diagnóstico, frequente na literatura, de descentralização e falta de coordenação nacional dos partidos. No que se refere às estratégias coligacionistas dos partidos relevantes, esse diagnóstico parece aplicarse apenas ao PMDB, PDS-PP e PTB.

De uma eleição para outra, os partidos relevantes apresentam correlação bem menor na distribuição do número de alianças feitas para a mesma Casa. O único partido que apresenta coeficiente $r=1,0$ é o PT, entre 1990 e 1994, nas eleições para a Câmara e governadorias. Os menores coeficientes são encontrados nas disputas para o Senado, o que certamente está relacionado com a variação no número de cadeiras em disputa entre uma eleição e outra. Cabe salientar, por fim, que a exigência de verticalização, especialmente a de 2002, introduziu um desvio ainda mais significativo no padrão aliancista dos partidos relevantes: todos eles apresentaram queda mais ou menos significativa no coeficiente de correlação entre 1998 e 2002 e 2002 e 2006.

Cabe destacar, por fim, que a disposição dos partidos, na Tabela 7 , foi feita de acordo com sua posição no espectro ideológico (da esquerda para a direita, na linha e na coluna) e com o número de alianças, o que revela suas preferências e resistências ideológicas na formação das coligações. Nesse aspecto, verifica-se que, no atual período democrático, todos os partidos relevantes fizeram alianças entre si, em pelo menos um distrito eleitoral nas disputas para os três cargos, independentemente de sua posição no espectro ideológico. Em segundo lugar, observam-se variações importantes entre as extremidades da distribuição: na extremidade superior esquerda (alianças entre PT, PC do B e PSB) e na extremidade inferior direita (alianças entre PFL, PDS-PP e PTB) temos valores bem superiores aos encontrados na extremidade superior direita (alianças entre o PFL, PDS-PP e PB com PT, $\mathrm{PC}$ do B e PSB). Esse padrão ocorre nas distribuições do número de alianças para os três cargos. Dessa perspectiva, os dados parecem indicar certa incidência da tese de resistência ideológica, em pelo menos alguns distritos eleitorais, também no atual período democrático. Mas, se olharmos para o centro superior das distribuições, verificamos queda semelhante à verificada na extremidade superior direita. Nesse ponto das distribuições, são apresentados os números das alianças do PSDB e do PMDB com os partidos de esquerda. Essa diferença relaciona-se com a resistência política, derivada da bipolarização da disputa presidencial.

Os dados da Tabela 8 permitem qualificar melhor a tese de resistência ideológica entre os partidos relevantes, nas seis últimas eleições e para os três cargos, por bloco ideológico. 
REVISTA DE SOCIOLOGIA E POLÍTICA V. 21, Nº 47: 69-90 SET. 2013

TABELA 8 - ALIANÇAS ENTRE OS PARTIDOS RELEVANTES, POR CASA, POSIÇÃO IDEOLÓGICA E ELEIÇÃO (19902010) $(\%)$

\begin{tabular}{|c|c|c|c|c|c|c|c|c|c|}
\hline \multirow{2}{*}{ Eleição } & \multicolumn{3}{|c|}{ Esquerda cl } & \multicolumn{2}{|c|}{ Centro cl } & \multirow{2}{*}{$\frac{\text { Direita cl }}{\text { Direita }}$} & \multirow{2}{*}{$\begin{array}{c}\text { Intra- } \\
\text { blocos }\end{array}$} & \multirow{2}{*}{$\begin{array}{l}\text { Extra- } \\
\text { blocos }\end{array}$} & \multirow{2}{*}{$\begin{array}{c}\text { Total } \\
\text { (N) }\end{array}$} \\
\hline & Esquerda & Centro & Direita & Centro & Direita & & & & \\
\hline \multicolumn{10}{|c|}{ Câmara dos Deputados } \\
\hline 1990 & 37,1 & 15,8 & 6,7 & 2,5 & 13,3 & 24,6 & 64,2 & 35,8 & (240) \\
\hline 1994 & 42,2 & 11,6 & 12,5 & 3,6 & 13,7 & 16,4 & 62,2 & 37,8 & (329) \\
\hline 1998 & 31,5 & 9,4 & 16,3 & 2,2 & 20,7 & 19,9 & 53,6 & 46,4 & (362) \\
\hline 2002 & 21,3 & 0,0 & 42,1 & 5,9 & 16,3 & 14,4 & 41,6 & 58,4 & (202) \\
\hline 2006 & 22,6 & 11,1 & 28,3 & 2,2 & 18,5 & 17,2 & 42,0 & 57,9 & (314) \\
\hline 2010 & 23,7 & 15,6 & 31,2 & 1,5 & 16,1 & 11,8 & 37,0 & 62,9 & (397) \\
\hline \multicolumn{10}{|c|}{ Senado Federal } \\
\hline 1990 & 46,2 & 15,9 & 5,6 & 3,3 & 10,0 & 18,9 & 68,4 & 31,6 & (301) \\
\hline 1994 & 43,7 & 16,8 & 9,6 & 3,0 & 13,7 & 13,2 & 59,9 & 40,1 & (197) \\
\hline 1998 & 33,1 & 8,3 & 14,3 & 1,7 & 22,3 & 20,3 & 55,1 & 44,9 & (350) \\
\hline 2002 & 21,0 & 0,0 & 43,0 & 6,0 & 17,5 & 12,5 & 39,5 & 60,5 & (200) \\
\hline 2006 & 18,6 & 10,2 & 30,2 & 1,5 & 19,5 & 20,1 & 40,2 & 59,9 & (344) \\
\hline 2010 & 22,7 & 16,4 & 33,9 & 1,4 & 15,0 & 10,7 & 34,8 & 65,3 & (507) \\
\hline \multicolumn{10}{|c|}{ Governadorias } \\
\hline 1990 & 41,9 & 15,1 & 5,2 & 2,7 & 12,4 & 22,7 & 67,3 & 32,7 & (291) \\
\hline 1994 & 40,3 & 17,0 & 11,7 & 3,2 & 12,7 & 15,2 & 58,7 & 41,4 & (283) \\
\hline 1998 & 29,2 & 9,4 & 16,0 & 2,0 & 22,9 & 20,5 & 51,7 & 48,3 & (449) \\
\hline 2002 & 19,3 & 0,0 & 42,6 & 6,4 & 17,3 & 14,4 & 40,1 & 59,9 & (202) \\
\hline 2006 & 18,5 & 11,9 & 29,3 & 1,8 & 19,5 & 19,0 & 39,3 & 60,7 & (379) \\
\hline 2010 & 22,6 & 15,8 & 35,1 & 1,3 & 14,2 & 10,9 & 34,8 & 65,1 & (530) \\
\hline
\end{tabular}

FONTE: A autora, a partir de dados do Tribunal Superior Eleitoral (TSE), Schmitt (2000), Carreirão (2006) e Nicolau (2006).

A partir dos dados da Tabela 8, verifica-se, em primeiro lugar, que os partidos relevantes apresentam evolução similar do percentual de alianças nas eleições para a Câmara, Senado e Governadorias. Essa similaridade era esperada, dados os altos coeficientes de correlação nas distribuições de alianças feitas para cada cargo, encontrados anteriormente.

Na evolução do número de alianças, observa-se, em segundo lugar, a diminuição gradativa, ao longo do período, do percentual de alianças entre os partidos de esquerda (PT, PC do B, PSB, PDT e PPS). A tendência é praticamente similar nas eleições para a Câmara, Senado e governadorias, havendo apenas uma pequena variação: nas eleições para a Câmara, o maior percentual de alianças entre os partidos de esquerda foi em 1994 (42,2\% das 240 do total de alianças feitas pelos partidos relevantes; um aumento de $5 \%$ em relação às eleições de 1990); para o Senado e governadorias, o maior percentual dessas alianças foi em 1990 (46,2\% e 41,9\% do total de alianças, respectivamente). Em 2010, os percentuais de alianças entre esses partidos são de $23,7 \%, 22,7 \%$ e $22,6 \%$ para a Câmara, Senado e governadorias, respectivamente, quase a metade dos observados em 1990.

Cabe destacar que, além do aumento do número absoluto de alianças de todos os partidos de esquerda com partidos de outros blocos ideológicos, essa queda nos percentuais de alianças entre eles, foi provocada pelo PPS: em 1998, esse partido já equilibrava suas alianças entre a esquerda e a direita; em 2002, quando apresentou candidato presidencial próprio (Ciro Gomes), o PPS aliou-se exclusivamente ao PDT, PTB, PDS-PP e PFL, deslocando seu alinhamento, assim, para a direita; em 2006 e 2010, esse partido passou a apoiar os candidatos presidenciais do PSDB, estabelecendo, respectivamente, 58 e 67 alianças ao centro e à direita e apenas 14 e 21 à esquerda, também respectivamente.

Em terceiro lugar, verifica-se que, correlativamente à queda no percentual de alianças entre os partidos de esquerda, há aumento nos percentuais das alianças entre eles e os partidos de direita (PFL/DEM, PDSPP, PTB e PL): em 1990, o percentual de alianças entre esses partidos, nas eleições para a Câmara, Senado e governadorias, foi de $6,7 \%, 5,6 \%$ e $5,2 \%$, respectivamente; em 2010 , de $31,2 \%, 33,9 \%$ e $35,1 \%$, também respectivamente.

Entre os principais fatores que explicam esse aumento das alianças entre os partidos de esquerda e de direita, cabe destacar o movimento de incorporação dos partidos de direita nas coligações do PT e de seus 
aliados mais leais, o que está significativamente relacionado com o aumento da competitividade de seus candidatos presidenciais, especialmente nas eleições de 2010. Esse movimento foi inaugurado em 2002, quando o PL/PR forneceu o candidato à vicepresidência (José Alencar) da chapa que lançou o candidato petista (Luis Inácio Lula da Silva).

Em quarto lugar, constata-se que, entre os partidos de esquerda e os de centro (PSDB e PMDB), há queda nos percentuais de alianças até 2002, quando não há nenhuma aliança entre eles, seguida de crescimento dos percentuais que atingem, em 2010, praticamente o mesmo patamar dos verificados nas eleições de 1990, para os três cargos. Cabe lembrar que a ausência de alianças entre esses partidos em 2002 foi provocada pela verticalização, pois os partidos de esquerda compunham a coligação que lançou o candidato do $\mathrm{PT}$ à presidência, e o PMDB, a coligação que lançou $\mathrm{o}$ candidato do PSDB.

A última observação a ser feita, relativamente aos dados da Tabela 8, é a queda contínua nos percentuais de alianças formadas por partidos integrantes do mesmo bloco ideológico (alianças intrablocos) e o correlato aumento nos percentuais de alianças formadas por partidos que integram blocos diferentes (alianças extrablocos $)\left(8^{\mathrm{a}}\right.$ e $9^{\mathrm{a}}$ colunas da Tabela 8 , respectivamente). O percentual de alianças extrablocos aumentou, entre 1990 e 2010 , de $35,8 \%$ para $62,9 \%$ do total de alianças feitas para a Câmara; de 31,6\% para $65,3 \%$, para o Senado; de $32,7 \%$ para $65,1 \%$, para as governadorias.

Pode-se dizer, portanto, que houve uma diminuição da resistência ideológica no cálculo coligacionista. Em termos percentuais, entre 1990 e 2010 , os partidos relevantes aumentaram em $27,1 \%, 33,7 \%$ e $32,4 \%$ o número de alianças com parceiros externos aos seus respectivos blocos ideológicos, nas disputas para a Câmara, Senado e governadorias, respectivamente. O movimento está, pois, na mesma direção do encontrado nos estudos sobre o período de 1950 a 1962, e posterior a 1986: diluição da motivação ideológica no cálculo coligacionista em favor de um comportamento estratégico, isto é, orientado para ganhos eleitorais.

O ponto importante a ser salientado aqui é que esse achado - diluição da resistência ideológica - não implica necessariamente desaparecimento de toda e qualquer resistência ideológica, nem ausência de resistências de outro tipo. Na análise da Tabela 7, foi apontado o maior número de alianças entre os três partidos situados nas extremidades da distribuição (à esquerda e à direita), em relação ao número de alianças feitas entre os partidos de esquerda, entre os de direita e entre os de esquerda e de centro. Essas diferenças só adquirem sentido se considerarmos, na análise da racionalidade das estratégias coligacionistas, tanto a resistência ideológica quanto a resistência política, gerada pela bipolarização que se instalou na disputa presidencial entre o PT e o PSDB e seus principais aliados.

A partir dos dados da Tabela 9, é possível avaliar a evolução das alianças entre os dois partidos de vocação presidencial, nas eleições de 1990 a 2010 para os três cargos.

TABELA 9 - ALIANÇAS ENTRE PT E PSDB, POR CASAE ELEIÇÃO (1990-2010) (N).

\begin{tabular}{|l|c|c|c|}
\hline Eleição & Câmara & Senado & Governadorias \\
\hline 1990 & 3 & 3 & 3 \\
1994 & 2 & 1 & 2 \\
1998 & 2 & 2 & 2 \\
2002 & 0 & 0 & 0 \\
2006 & 0 & 0 & 0 \\
2010 & 0 & 0 & 0 \\
\hline
\end{tabular}

FONTE: A autora, a partir de dados do Tribunal Superior Eleitoral (TSE), Schmitt (2000), Carreirão (2006) e Nicolau (2006).

O PT e o PSDB estiveram juntos em três coligações nas disputas para a Câmara, Senado e governadorias, em 1990; em duas coligações, nas eleições para a Câmara e governadorias, e em uma para o Senado, em 1994; e, por fim, em duas coligações para os três cargos, em 1998. Nos anos seguintes, nas disputas para os três cargos, não houve nenhuma aliança entre esses partidos. Os coadjuvantes seguem, em geral, o mesmo padrão. Considerando apenas as eleições para a Câmara, temos que o número de alianças do PSDB com o PC do B foi de seis, duas e duas, em 1990, 1994 e 1998, respectivamente; com o PSB, o número de alianças do PSDB é de três, seis, seis e três, em 1990, 1994, 1998 e 2010, respectivamente ${ }^{11}$. A restrição das alianças entre esses partidos, antes de 2002, adquire relevância ainda maior se considerarmos o contexto de significativa ampliação do número de alianças entre todos os partidos, conforme visto anteriormente.

Cabe ressaltar que, entre PT e PFL, a resistência é anterior a 2002 e até mais radical que a que se instalou entre o PT e o PSDB. Nas eleições para a Câmara e para o Senado, esses dois são os únicos partidos que

11 Para as governadorias, esses partidos fizeram um maior número de alianças, conforme mostrado nas tabelas 1,2 e 3 do Anexo. 
nunca se haviam aliado até 2010, quando compuseram uma mesma coligação para a Câmara e para o Senado. Nas disputas para as governadorias, esses partidos também se colocaram sempre em campos opostos, exceto em 2002, quando integraram uma mesma coligação em Roraima - a que lançou o candidato do PSL -, e, em 2010, quando integraram a mesma coligação no Maranhão - a que lançou o candidato do PRB.

O comportamento do PT e do PFL/DEM mostra, assim, que a resistência ideológica no cálculo coligacionista dos partidos relevantes encontra pelo menos uma evidência radical no sistema atual, no sentido de abranger praticamente todo o território nacional. Mas é preciso reconhecer que, apesar de seu caráter pontual, em termos partidários, essa resistência ideológica imprime, na resistência política, fundada na bipolarização pelo cargo presidencial, um caráter também ideológico e não apenas político.

No que se refere à resistência política entre as duas coalizões que têm apresentado maior competitividade na disputa pelo cargo presidencial, poder-se-ia argumentar que ela foi forçada pela exigência de verticalização em 2002 e 2006. Contra esse argumento, ressalta-se, em primeiro lugar, que a resistência política entre PT e o PSDB já existia mesmo antes da exigência de verticalização em 2002: eles fizeram apenas duas alianças em 1998, em todo o território nacional, nas disputas para Câmara, Senado e governadorias; em segundo lugar, salienta-se que, nas eleições de 2006, todos os partidos, prevendo a vigência da verticalização e visando à acomodação diversificada do maior número de parceiros nos diversos pleitos, restringiram ao máximo as coligações presidenciais. Apenas PT e PCdoB, de um lado, e PSDB e PFL, de outro, formalizaram coligações; por fim, em terceiro lugar, destaca-se que, em 2010, quando não havia qualquer restrição externa às considerações político-partidárias para a formação das coligações, PT e PSDB não fizeram nenhuma aliança; PT e PFL/DEM aliaram-se apenas no Maranhão.

\section{CONCLUSÕES}

A análise das coligações e alianças realizadas nas eleições para a Câmara dos Deputados, Senado Federal e governadorias, no período de 1990 a 2010, revelou, em primeiro lugar, a efetividade dos incentivos políticos e institucionais para que os partidos vinculem as estratégias coligacionistas estabelecidas nessas eleições às configuradas na disputa presidencial; em segundo lugar, a análise desvendou padrões, tendências e racionalidades consistentes no comportamento eleitoral dos partidos brasileiros, em geral, e, em particular, nas coligações e alianças estabelecidas pelos partidos relevantes.

No que se refere à participação eleitoral dos partidos relevantes e dos micros, verificou-se sua dispersão no território nacional. Focando nos 11 partidos relevantes, sua participação nas eleições para a Câmara, Senado e governadorias, em 1990, ocorreu em 95,3\%, 90,2\% e $78,5 \%$ dos distritos eleitorais, respectivamente; em 2010, essa participação atingiu 99,3\%, 95,3\% e 95,3\% dos distritos, também respectivamente.

Essa dispersão da participação eleitoral no território nacional traduziu-se no significativo aumento do número de participações dos partidos relevantes e dos micros nas eleições para os três cargos, ao longo do período. Entre os micros, o aumento da participação foi, nas eleições para a Câmara, Senado e governadorias, de $38,3 \%, 110,9 \%$ e $171,5 \%$, respectivamente; entre os partidos relevantes, o aumento foi de $4,2 \%, 5,6 \%$ e $21,5 \%$, também respectivamente. Verificou-se ainda que os partidos relevantes e os micros participaram mais das eleições proporcionais que das eleições majoritárias. Entre os micros, a participação para o Senado e as governadorias foi, em média, 38,2\% e 27,7\% menor que para a Câmara; entre os partidos relevantes, 13\% e $11 \%$, respectivamente.

No que se refere às coligações, verificou-se, em primeiro lugar, que a variabilidade em sua quantidade total esconde significativa estabilidade no número daquelas realizadas pelos partidos relevantes e pelos micros, especialmente se excluídas as eleições desviantes. Entre os partidos relevantes, a média de coligações constituídas por eles e micros, nas eleições para a Câmara, Senado e governadorias é de 89, 72 e 75 , respectivamente. No que se refere às coligações constituídas apenas por micros, também para a Câmara, Senado e governadorias, a média é de 14, seis e oito, respectivamente.

Quanto às modalidades de participação eleitoral, verificou-se forte preferência dos dois tipos de partido pela coligação. No que se refere aos micros, sua preferência por essa modalidade foi, nas eleições para a Câmara, Senado e governadorias, de 71,3\%, 78,1\% e $81,2 \%$, respectivamente; quanto aos partidos relevantes, a preferência pela participação eleitoral em coligação tem sido ainda maior que a verificada entre os micros: nas eleições para a Câmara e Senado, 88\% de sua participação eleitoral foram em coligação; para as governadorias, 94\%. Constatou-se também que essa preferência pela participação eleitoral em coligação cresceu 23,4\%, 20,7\% e 9,6\% nas eleições para o Senado, Câmara e governadorias, respectivamente, ao longo do período. 
$\mathrm{Na}$ avaliação dessas tendências da participação eleitoral dos partidos relevantes e dos micros, foi verificado o impacto da verticalização das coligações sobre as estratégias coligacionistas, especialmente em 2002. Naquela eleição, houve aumento do número de coligações entre os partidos relevantes e da incorporação dos micros nessas coligações, correlato à diminuição do número de alianças entre os partidos relevantes. Esse achado, além do significativo salto no número de coligações para a Câmara entre 1990 e 1994, avaliado em conjunto com a configuração ideológica das alianças que as constituíram, permite inferir que quanto mais restrições legais ou ideológicas há sobre as estratégias coligacionistas, maior o número de coligações entre os partidos relevantes.

$\mathrm{Na}$ avaliação das alianças realizadas pelos partidos relevantes, chamou-se a atenção, em primeiro lugar, para o fato de que a dispersão de sua participação eleitoral no território nacional ocorreu em um contexto de marcada estabilidade no número de coligações. Assim, esse aumento foi possível pelo significativo crescimento do tamanho das coligações, isto é, pela ampliação do número de alianças entre esses partidos. Nas eleições para Câmara, Senado e governadorias, entre 1990 e 2010, a ampliação do número de alianças foi de $65,4 \%, 68,4 \%$ e $82,1 \%$, respectivamente.

A avaliação das alianças entre os partidos relevantes permitiu verificar, finalmente, a replicação do padrão de preferências e resistências que emergiu na disputa presidencial nas eleições para a Câmara, Senado e governadorias. A bipolarização entre as duas coalizões de maior competitividade na disputa pelo cargo presidencial, lideradas pelo PT e pelo PSDB, traduziuse em uma resistência política, entre os partidos que as integram, nas estratégias coligacionistas para os cargos legislativos federais e majoritários estaduais, que se sobrepôs à tradicional resistência ideológica.
No que se refere a esta, foi mostrada sua diluição, mas não seu desaparecimento ao longo do período: entre 1990 e 2010, os partidos relevantes aumentaram em $27,1 \%, 33,7 \%$ e $32,4 \%$ o número de alianças com parceiros externos aos seus respectivos blocos ideológicos, nas disputas para a Câmara, Senado e governadorias, respectivamente. Apesar da diluição, verificou-se, em 2010, a existência de um ainda significativo número de alianças feitas entre partidos que integram o mesmo bloco ideológico $(37 \%$ das alianças nas eleições para a Câmara; $34,8 \%$ nas eleições para o Senado e governadorias) e pelo menos uma manifestação radical de resistência ideológica no período atual: a existente entre PT e o PFL/DEM, o que imprime à resistência política, que emergiu entre as duas coalizões de maior competitividade na disputa pelo cargo presidencial, um caráter também ideológico.

Além da resistência política entre os partidos integrantes das duas coalizões mais competitivas na disputa presidencial, verificou-se que esses partidos também se destacam dos outros partidos relevantes quanto ao grau de coordenação de suas estratégias coligacionistas. Na comparação das distribuições do número de alianças realizadas pelos partidos, nos três cargos, em um mesmo ano eleitoral, constatou-se que o PT, PC do B, PSB e PFL apresentam coeficientes mais altos de correlação que os verificados entre os outros partidos, especialmente o PMDB, PTB e PPPDS. A exceção encontrada foi o PSDB, que apresentou coeficientes de correlação um pouco mais baixos que o PT, mas apenas no início do período, isto é, antes de sua emergência como partido de vocação presidencial. Esse achado qualifica, portanto, o diagnóstico de que os partidos brasileiros carecem de centralização ou de coordenação nacional de suas estratégias eleitorais. Os dados mostram que, entre os partidos relevantes, esse diagnóstico aplica-se mais consistentemente apenas ao PMDB, PDS-PP e PTB.

Geralda Luiza de Miranda (geraldaluiza@fafich.ufmg.br) é Doutora em Ciência Política pela Universidade Federal de Minas Gerais (UFMG) e professora de Ciência Política na mesma universidade.

\section{REFERÊNCIAS BIBLIOGRÁFICAS}

ABRUCIO, F. L. 1998. Os barões da federação. São Paulo: Hucitec

BRAGA, M. S. 2006a. O processo partidário-eleitoral brasileiro. Padrões de competição política (1982-2002). São Paulo: Humanitas.

.2006b. Dinâmica de coordenação eleitoral em regime presidencialista e federativo: determinantes e consequências das coligações partidárias no Bra- sil. In: SOARES, G. A. D. \& RENNÓ, L. R. (orgs.). Reforma Política: lições da história recente. Rio de Janeiro: FGV.

CARREIRÃO, Y. S. 2006. Ideologia e partidos políticos: um estudo sobre coligações em Santa Catarina. Opinião Pública, Campinas, v. 12, n. 1, p. 136163, abr.-maio. Disponível em: http:// www.scielo.br/pdf/op/v12n1/29401. Acesso em: 13.ago.2013. 
CARREIRÃO, Y. S. \& NASCIMENTO, F. P. 2010. As coligações nas eleições para os cargos de governador, senador, deputado federal e deputado estadual no Brasil (1986/2006). Revista Brasileira de Ciência Política, Brasília, n. 4, p. 75-104, jul.dez. Disponível em: http://seer.bce.unb.br/ index.php/rbcp/article/viewFile/6519/5262. Acesso em: 13.ago.2013.

DANTAS, H. 2007. Coligações em eleições majoritárias municipais: a lógica do alinhamento dos partidos políticos brasileiros nas disputas de 2000 e 2004 . São Paulo. Tese (Doutorado em Ciência Política). Universidade de São Paulo.

FIGUEIREDO, A. \& LIMONGI, F. 1999. Executivo e Legislativo na nova ordem constitucional. Rio de Janeiro: FGV.

2008. Política orçamentária no presidencialismo de coalizão. Rio de Janeiro: FGV.

FLEISCHER, D. 2010. Articulação de coligações no Brasil: antes e depois da verticalização (1994 e 1998 versus 2002 e 2006): impactos sobre os partidos. In: KRAUSE, S. \& SCHMITT, R. (orgs.). Partidos e coligações eleitorais no Brasil. Rio de Janeiro: Konrad Adenauer.

KRAUSE, S. 2005. Uma análise comparativa das estratégias eleitorais nas eleições majoritárias (19941998-2002): coligações eleitorais X nacionalização dos partidos e do sistema partidário brasileiro. In: KRAUSE, S.; DANTAS, H. \& MIGUEL, L. F. (orgs.). Coligações partidárias na nova democracia brasileira: perfis e tendências. Rio de Janeiro: Konrad Adenauer.

KRAUSE, S. \& GODOI, P. P. 2010. Coligações eleitorais para os executivos estaduais (1986-2006): padrões e tendências. In: KRAUSE, S.; DANTAS, H. \& MIGUEL, L. F. (orgs.). Coligações partidárias na nova democracia brasileira: perfis e tendências. Rio de Janeiro: Konrad Adenauer.

LAVAREDA, A. 1991. A democracia nas urnas: o processo partidário eleitoral brasileiro. Rio de Janeiro: IUPERJ.

LEONI, E. L. 2011. Coligações e ideologia nas eleições para vereadores no Brasil: uma análise econométrica. In: POWER, T. J. \& ZUCCO JR., C. (orgs.). O Congresso por ele mesmo: autopercepções da classe política brasileira. Belo Horizonte: UFMG.

LIMA JÚNIOR, O. B. 1983. Os partidos políticos brasileiros: a experiência federal e regional (19451964). Rio de Janeiro: Graal.
1997. A reimplantação do multipartidarismo: efeitos institucionais e contextuais. In:

(org.). O sistema partidário brasileiro. Rio de Janeiro: FGV.

MACHADO, A. 2005. A lógica das coligações no Brasil. In: KRAUSE, S. \& SCHMITT, R. (orgs.). Partidos e coligações eleitorais no Brasil. Rio de Janeiro: Konrad Adenauer.

MACHADO, C. M. M. \& MIGUEL, L. F. 2008. Coerência, coesão e consistência: uma proposta de tipologia para coligações municipais. Trabalho apresentado no $6^{\circ}$ Encontro da $\mathrm{ABCP}$, realizado em Campinas, de 29 de julho a $1^{\circ}$ de agosto. Digit.

MAINWARING, S. 1993. Democracia presidencialista multipartidária: O caso do Brasil. Lua Nova, São Paulo, n. 28-29, p. 21-74, abr. Disponível em: http:/ /www.scielo.br/scielo.php?pid=S 0102 $64451993000100003 \&$ script $=$ sci_arttext. Acesso em: 13.ago.2013.

1999. Sistemas partidários em novas democracias: o caso do Brasil. Rio de Janeiro: FGV.

MARCHETTI, V. 2010. O TSE (Tribunal Superior Eleitoral) e a "verticalização" das coligações. In: KRAUSE, S. \& SCHMITT, R. (orgs.). Partidos e coligações eleitorais no Brasil. Rio de Janeiro: Konrad Adenauer.

MELO, C. R. 2006. Sistema partidário, presidencialismo e reforma política no Brasil. In: SOARES, G. A. D. \& RENNÓ, L. R. (orgs.). Reforma Política: lições da história recente. Rio de Janeiro: FGV.

.2010. Eleições presidenciais jogos aninhados e sistema partidário no Brasil. Revista Brasileira de Ciência Política, Brasília, n. 4, p. 13-42, jul.-dez. Disponível em: http://seer.bce.unb.br/index.php/ rbcp/article/viewFile/6517/5260

MIGNOZZETTI, U. G.; GALDINO, M. \& BERNABEL, R. T. 2011. Um modelo para explicar as coligações eleitorais para a Câmara federal brasileira (1998-2006). Revista Política Hoje, Recife, v. 20, n. 2, p. 741-788. Disponível em: http:/ /www.revista.ufpe.br/politicahoje/index.php/ politica/article/view/132/99. Acesso em: 13.ago.2013.

MIRANDA, G. L. 2009. A influência da dinâmica eleitoral sobre o comportamento dos partidos na Câmara dos Deputados e no Senado Federal. Dados, Rio de Janeiro, v. 52, n. 4, p. 911-959. Disponível em: http://www.scielo.br/pdf/dados/v52n4/ v52n4a04.pdf. Acesso em: 15.ago.2013.

NICOLAU, J. 1996. Multipartidarismo e democra- 
cia: um estudo sobre o sistema partidário brasileiro (1985-1994). Rio de Janeiro: FGV.

. 2006. Bando de dados eleitorais do Brasil (1982-2006). Digit.

NOVAES, C. A. M. 1994. Dinâmica institucional da representação: individualismo e partidos na Câmara dos Deputados. Novos Estudos, São Paulo, n. 38, p. 99-147.

PEIXOTO, V. M. 2010. Coligações eleitorais nos municípios brasileiros: competição e estratégia. In: KRAUSE, S.; DANTAS, H. \& MIGUEL, L. F. (orgs.). Coligações partidárias na nova democracia brasileira: perfis e tendências. Rio de Janeiro: Konrad Adenauer.

RIBEIRO, P. J. F. 2005. Acordos partidários nacionais, reflexos locais: o presidencialismo de coalizão enquanto fator estruturante das alianças eleitorais municipais. Trabalho apresentado no XXIX Encontro Anual da Anpocs, realizado em Caxambu (MG), de 25 a 29 de outubro. Digit.

SAMUELS, D. 2003. Ambition, Federalism, and Legislative Politics in Brazil. Cambridge (UK): University of Cambridge.

SANTOS, W. G. 1987. Crise e castigo: partidos e generais na política brasileira. Rio de Janeiro: Vértice.
SARTORI, G. 1982. Partidos e sistemas partidários. Brasília: UNB.

SCHMITT, R. 2000. Partidos politicos no Brasil (1945-2000). Rio de Janeiro: J. Zahar.

2003. A nacionalização dos partidos políticos brasileiros. In: TAVARES, J. A. G. \& MELO, C. R. (orgs.). O sistema partidário na consolidação da democracia brasileira. Brasília: Instituto Teotônio Vilela.

SHUGART, M. \& CAREY, J. 1992. Presidents and Assemblies: constitutional design and electoral dynamics. Cambridge (UK): University of Cambridge.

SOARES, G. A. D. 1964. Alianças e coligações eleitorais: notas para uma teoria. Revista Brasileira de Estudos Políticos, Belo Horizonte, n. 17, p. 95124.

SOUSA, V. 2005. O comportamento das coligações eleitorais entre 1954-1962: pleitos majoritários coincidentes com proporcionais. In: KRAUSE, S. \& SCHMITT, R. (orgs.). Partidos e coligações eleitorais no Brasil. Rio de Janeiro: Konrad Adenauer.

SOUZA, M. C. 1983. Estado e partidos políticos no Brasil (1930-1964). São Paulo: Alfa-Ômega.

ANEXO

TABELA 1 - ALIANÇAS ENTRE PARTIDOS RELEVANTES PARAA CÂMARA DOS DEPUTADOS, POR ELEIÇÃO (19902010) (N)

\begin{tabular}{|lccccccccccc|}
\hline Partido & Ano & PCdoB & PSB & PDT & PCB/PPS & PSDB & PMDB & PL/PR & PTB & PDS-PP & PFL/DEM \\
\hline PT & 1990 & 10 & 12 & 4 & 9 & 3 & - & - & - & - & - \\
& 1994 & 20 & 17 & 7 & 15 & 2 & 1 & - & - & - & - \\
& 1998 & 19 & 15 & 11 & 6 & 2 & - & 1 & 2 & 1 & - \\
& 2002 & 26 & - & - & - & - & - & 18 & - & - & - \\
& 2006 & 27 & 16 & - & 1 & - & 5 & 10 & 5 & 3 & - \\
& 2010 & 15 & 15 & 11 & 3 & & 11 & 13 & 6 & 8 & 1 \\
\hline PCdoB & 1990 & & 12 & 8 & 13 & 6 & 1 & & 1 & - & - \\
& 1994 & & 21 & 8 & 19 & 2 & 4 & 4 & 2 & - & 1 \\
& 1998 & & 13 & 13 & 8 & 2 & 3 & 3 & 4 & 1 & 2 \\
& 2002 & & - & - & - & - & - & 17 & - & - & - \\
& 2006 & & 14 & & 1 & 0 & 4 & 10 & 6 & 2 & \\
& 2010 & & 11 & 15 & 2 & & 11 & 12 & 4 & 8 & 3 \\
\hline PSB & 1990 & & & 5 & 9 & 3 & 1 & - & 1 & 1 & 1 \\
& 1994 & & & 9 & 16 & 6 & 3 & 2 & 1 & 1 & 1 \\
& 1998 & & & 13 & 8 & 6 & 1 & 3 & 3 & 3 & 1 \\
& 2002 & & & - & - & - & - & - & - & 2 & - \\
& 2006 & & & 4 & 3 & - & 5 & 9 & 8 & 6 & - \\
& 2010 & & & 12 & 6 & 3 & 6 & 9 & 4 & 7 & 3 \\
\hline
\end{tabular}


REVISTA DE SOCIOLOGIA E POLÍTICA V. 21, Nº 47: 69-90 SET. 2013

\begin{tabular}{|c|c|c|c|c|c|c|c|c|}
\hline \multirow[t]{6}{*}{ PDT } & 1990 & 7 & 9 & 6 & - & 6 & 3 & 2 \\
\hline & 1994 & 7 & 8 & 4 & 3 & 10 & 2 & 6 \\
\hline & 1998 & 8 & 6 & 3 & 5 & 6 & 5 & 2 \\
\hline & 2002 & 17 & - & - & - & 15 & 5 & 1 \\
\hline & 2006 & 5 & - & 2 & 3 & 2 & 4 & - \\
\hline & 2010 & 4 & 2 & 6 & 9 & 3 & 1 & 3 \\
\hline PCB & 1990 & & 6 & 3 & - & 1 & - & - \\
\hline \multirow[t]{5}{*}{ PPS } & 1994 & & 5 & 3 & 3 & 2 & 2 & 1 \\
\hline & 1998 & & 6 & 5 & 7 & 4 & 4 & 2 \\
\hline & 2002 & & - & - & - & 14 & 7 & 6 \\
\hline & 2006 & & 11 & 8 & 4 & 3 & 3 & 11 \\
\hline & 2010 & & 17 & 6 & 3 & 5 & 7 & 15 \\
\hline \multirow[t]{6}{*}{ PSDB } & 1990 & & & 6 & 4 & 1 & 2 & 3 \\
\hline & 1994 & & & 12 & 6 & 7 & 6 & 7 \\
\hline & 1998 & & & 8 & 10 & 9 & 8 & 10 \\
\hline & 2002 & & & 12 & - & - & 9 & 12 \\
\hline & 2006 & & & 7 & 6 & 9 & 7 & 13 \\
\hline & 2010 & & & 6 & 6 & 4 & 5 & 20 \\
\hline \multirow[t]{6}{*}{ PMDB } & 1990 & & & & 6 & 4 & 6 & 6 \\
\hline & 1994 & & & & 6 & 2 & 6 & 5 \\
\hline & 1998 & & & & 11 & 10 & 8 & 9 \\
\hline & 2002 & & & & - & - & 5 & 7 \\
\hline & 2006 & & & & 4 & 6 & 6 & 7 \\
\hline & 2010 & & & & 10 & 5 & 5 & 9 \\
\hline \multirow[t]{5}{*}{ PL } & 1990 & & & & & 6 & 8 & 10 \\
\hline & 1994 & & & & & 10 & 4 & 8 \\
\hline & 1998 & & & & & 12 & 13 & 12 \\
\hline & 2002 & & & & & - & 1 & 2 \\
\hline & 2006 & & & & & 11 & 9 & 8 \\
\hline PR & 2010 & & & & & 6 & 9 & 7 \\
\hline \multirow[t]{6}{*}{ PTB } & 1990 & & & & & & 11 & 11 \\
\hline & 1994 & & & & & & 6 & 13 \\
\hline & 1998 & & & & & & 8 & 14 \\
\hline & 2002 & & & & & & 8 & 5 \\
\hline & 2006 & & & & & & 10 & 8 \\
\hline & 2010 & & & & & & 10 & 7 \\
\hline PDS & 1990 & & & & & & & 13 \\
\hline PPR & 1994 & & & & & & & 13 \\
\hline PPB & 1998 & & & & & & & 13 \\
\hline PPB & 2002 & & & & & & & 13 \\
\hline \multirow[t]{2}{*}{ PP } & 2006 & & & & & & & 8 \\
\hline & 2010 & & & & & & & 8 \\
\hline
\end{tabular}

FONTE: A autora, a partir de dados do Tribunal Superior Eleitoral (TSE), Schmitt (2000), Carreirão (2006) e Nicolau (2006). 
TABELA 2 - ALIANÇAS ENTRE OS PARTIDOS RELEVANTES PARA O SENADO FEDERAL, POR ELEIÇÃO (19902010) (N)

\begin{tabular}{|c|c|c|c|c|c|c|c|c|c|c|c|}
\hline Partido & Ano & PCdoB & PSB & PDT & PCB/PPS & PSDB & PMDB & PL/PR & PTB & PDS-PP & PFL/DEM \\
\hline \multirow[t]{6}{*}{ PT } & 1990 & 17 & 18 & 7 & 14 & 3 & - & - & - & - & - \\
\hline & 1994 & 11 & 12 & 3 & 10 & 1 & - & 1 & - & - & - \\
\hline & 1998 & 21 & 16 & 13 & 7 & 2 & 1 & 1 & 2 & 1 & - \\
\hline & 2002 & 25 & - & - & - & - & - & 18 & - & - & - \\
\hline & 2006 & 24 & 14 & & 2 & - & 5 & 10 & 5 & 3 & - \\
\hline & 2010 & 20 & 17 & 14 & 3 & - & 14 & 14 & 8 & 11 & 1 \\
\hline \multirow[t]{6}{*}{ PCdoB } & 1990 & & 18 & 15 & 18 & 10 & 2 & - & 1 & - & - \\
\hline & 1994 & & 12 & 6 & 12 & 5 & 2 & 1 & - & - & - \\
\hline & 1998 & & 14 & 12 & 7 & 2 & 3 & 2 & 3 & 1 & 2 \\
\hline & 2002 & & - & - & - & - & - & 18 & - & - & - \\
\hline & 2006 & & 14 & - & 2 & - & 5 & 10 & 5 & 3 & - \\
\hline & 2010 & & 13 & 17 & 2 & - & 15 & 13 & 6 & 11 & 3 \\
\hline \multirow[t]{6}{*}{ PSB } & 1990 & & & 8 & 13 & 5 & 2 & 1 & 2 & 1 & 1 \\
\hline & 1994 & & & 6 & 9 & 6 & 3 & 1 & 1 & - & 1 \\
\hline & 1998 & & & 12 & 8 & 6 & 1 & 5 & 4 & 2 & 2 \\
\hline & 2002 & & & - & - & - & - & - & - & 2 & - \\
\hline & 2006 & & & 3 & 4 & 2 & 5 & 11 & 9 & 7 & 2 \\
\hline & 2010 & & & 14 & 10 & 5 & 8 & 11 & 9 & 11 & 5 \\
\hline \multirow[t]{6}{*}{ PDT } & 1990 & & & & 11 & 12 & 5 & 1 & 5 & 2 & 1 \\
\hline & 1994 & & & & 5 & 6 & 3 & 2 & 5 & - & 2 \\
\hline & 1998 & & & & 6 & 2 & 1 & 3 & 3 & 3 & 1 \\
\hline & 2002 & & & & 17 & - & - & - & 15 & 5 & 2 \\
\hline & 2006 & & & & 1 & - & 2 & 2 & 1 & 3 & - \\
\hline & 2010 & & & & 5 & 3 & 10 & 11 & 6 & 12 & 4 \\
\hline \multirow[t]{6}{*}{ PPS } & 1990 & & & & & 6 & 3 & 1 & 1 & - & - \\
\hline & 1994 & & & & & 4 & 3 & 1 & 1 & 2 & 1 \\
\hline & 1998 & & & & & 7 & 4 & 5 & 4 & 5 & 1 \\
\hline & 2002 & & & & & - & - & - & 14 & 6 & 6 \\
\hline & 2006 & & & & & 10 & 6 & 7 & 6 & 6 & 14 \\
\hline & 2010 & & & & & 18 & 10 & 4 & 10 & 6 & 16 \\
\hline \multirow[t]{6}{*}{ PSDB } & 1990 & & & & & & 10 & 4 & 1 & 3 & 3 \\
\hline & 1994 & & & & & & 6 & 4 & 5 & 2 & 4 \\
\hline & 1998 & & & & & & 6 & 11 & 13 & 8 & 10 \\
\hline & 2002 & & & & & & 12 & - & - & 10 & 13 \\
\hline & 2006 & & & & & & 5 & 8 & 10 & 8 & 12 \\
\hline & 2010 & & & & & & 7 & 6 & 8 & 5 & 21 \\
\hline \multirow[t]{6}{*}{ PMDB } & 1990 & & & & & & & 7 & 3 & 4 & 5 \\
\hline & 1994 & & & & & & & 5 & - & 4 & 3 \\
\hline & 1998 & & & & & & & 10 & 8 & 8 & 10 \\
\hline & 2002 & & & & & & & - & - & 5 & 7 \\
\hline & 2006 & & & & & & & 5 & 7 & 10 & 7 \\
\hline & 2010 & & & & & & & 12 & 8 & 7 & 9 \\
\hline \multirow[t]{5}{*}{$P L$} & 1990 & & & & & & & & 6 & 7 & 9 \\
\hline & 1994 & & & & & & & & 5 & 2 & 4 \\
\hline & 1998 & & & & & & & & 12 & 12 & 12 \\
\hline & 2002 & & & & & & & & - & - & - \\
\hline & 2006 & & & & & & & & 13 & 13 & 10 \\
\hline PR & 2010 & & & & & & & & 8 & 11 & 7 \\
\hline \multirow[t]{6}{*}{ РTB } & 1990 & & & & & & & & & 11 & 11 \\
\hline & 1994 & & & & & & & & & 2 & 6 \\
\hline & 1998 & & & & & & & & & 10 & 14 \\
\hline & 2002 & & & & & & & & & 7 & 5 \\
\hline & 2006 & & & & & & & & & 12 & 10 \\
\hline & 2010 & & & & & & & & & 11 & 10 \\
\hline
\end{tabular}




\begin{tabular}{|llc|}
\hline PPR & 1990 & 13 \\
PPB & 1994 & 7 \\
PPB & 1998 & 11 \\
PP & 2002 & 13 \\
& 2006 & 11 \\
& 2010 & 7 \\
\hline
\end{tabular}

FONTE: A autora, a partir de dados do Tribunal Superior Eleitoral (TSE), Schmitt (2000), Carreirão (2006) e Nicolau (2006).

TABELA 3 -ALIANÇAS ENTRE PARTIDOS RELEVANTES PARAAS GOVERNADORIAS, POR ELEIÇÃO (1990-2010) (N)

\begin{tabular}{|c|c|c|c|c|c|c|c|c|c|c|c|}
\hline Partido & Ano & PCdoB & PSB & PDT & PPS & PSDB & PMDB & PL/PR & PTB & PDS-PP & PFLDEN \\
\hline \multirow[t]{6}{*}{ PT } & 1990 & 16 & 17 & 7 & 14 & 3 & - & - & - & - & - \\
\hline & 1994 & 14 & 15 & 5 & 13 & 2 & 1 & - & - & - & - \\
\hline & 1998 & 22 & 16 & 14 & 7 & 2 & 1 & 1 & 2 & 1 & - \\
\hline & 2002 & 25 & - & - & - & - & - & 18 & - & - & 1 \\
\hline & 2006 & 25 & 14 & - & 3 & - & 6 & 9 & 6 & 3 & - \\
\hline & 2010 & 21 & 17 & 15 & 3 & & 14 & 15 & 9 & 12 & 1 \\
\hline \multirow[t]{6}{*}{ PCdoB } & 1990 & & 15 & 14 & 13 & 9 & 2 & - & 1 & - & - \\
\hline & 1994 & & 18 & 8 & 14 & 6 & 5 & 3 & 1 & - & - \\
\hline & 1998 & & 15 & 15 & 9 & 2 & 4 & 3 & 4 & 1 & 2 \\
\hline & 2002 & & - & - & - & - & - & 18 & - & - & 1 \\
\hline & 2006 & & 14 & - & 3 & - & 6 & 9 & 6 & 3 & - \\
\hline & 2010 & & 14 & 17 & 3 & & 15 & 15 & 7 & 12 & 3 \\
\hline \multirow[t]{6}{*}{ PSB } & 1990 & & & 5 & 12 & 4 & 2 & 1 & - & - & - \\
\hline & 1994 & & & 8 & 13 & 6 & 5 & 3 & 2 & - & 1 \\
\hline & 1998 & & & 15 & 9 & 7 & 1 & 5 & 5 & 4 & 3 \\
\hline & 2002 & & & - & - & - & - & - & - & 2 & - \\
\hline & 2006 & & & 3 & 5 & 2 & 6 & 9 & 11 & 8 & 2 \\
\hline & 2010 & & & 15 & 10 & 5 & 8 & 12 & 9 & 12 & 5 \\
\hline \multirow[t]{6}{*}{ PDT } & 1990 & & & & 9 & 11 & 5 & 1 & 5 & 1 & 3 \\
\hline & 1994 & & & & 6 & 7 & 4 & 2 & 6 & 2 & 4 \\
\hline & 1998 & & & & 9 & 6 & 4 & 5 & 6 & 5 & 2 \\
\hline & 2002 & & & & 14 & - & - & - & 13 & 5 & 2 \\
\hline & 2006 & & & & 3 & - & 3 & 3 & 2 & 4 & - \\
\hline & 2010 & & & & 5 & 3 & 10 & 12 & 7 & 13 & 4 \\
\hline PCB & 1990 & & & & & 5 & 3 & 2 & 1 & - & - \\
\hline \multirow[t]{5}{*}{ PPS } & 1994 & & & & & 7 & 5 & 3 & 2 & 2 & 2 \\
\hline & 1998 & & & & & 8 & 7 & 8 & 7 & 6 & 2 \\
\hline & 2002 & & & & & - & - & - & 13 & 7 & 6 \\
\hline & 2006 & & & & & 13 & 9 & 7 & 8 & 6 & 15 \\
\hline & 2010 & & & & & 19 & 10 & 5 & 10 & 7 & 16 \\
\hline \multirow[t]{6}{*}{ PSDB } & 1990 & & & & & & 8 & 4 & 1 & 3 & 5 \\
\hline & 1994 & & & & & & 9 & 5 & 6 & 2 & 5 \\
\hline & 1998 & & & & & & 9 & 14 & 16 & 13 & 13 \\
\hline & 2002 & & & & & & 13 & - & - & 10 & 13 \\
\hline & 2006 & & & & & & 7 & 8 & 12 & 8 & 14 \\
\hline & 2010 & & & & & & 7 & 5 & 7 & 7 & 21 \\
\hline
\end{tabular}




\begin{tabular}{|c|c|c|c|c|c|}
\hline \multirow[t]{6}{*}{ PMDB } & 1990 & 9 & 2 & 4 & 8 \\
\hline & 1994 & 7 & 3 & 4 & 4 \\
\hline & 1998 & 14 & 12 & 10 & 11 \\
\hline & 2002 & - & - & 5 & 7 \\
\hline & 2006 & 11 & 11 & 2 & 8 \\
\hline & 2010 & 11 & 8 & 7 & 9 \\
\hline \multirow[t]{5}{*}{$P L$} & 1990 & & 8 & 10 & 13 \\
\hline & 1994 & & 8 & 4 & 5 \\
\hline & 1998 & & 15 & 15 & 15 \\
\hline & 2002 & & - & 1 & 2 \\
\hline & 2006 & & 13 & 13 & 10 \\
\hline PR & 2010 & & 10 & 11 & 7 \\
\hline \multirow[t]{6}{*}{ PTB } & 1990 & & & 9 & 12 \\
\hline & 1994 & & & 6 & 11 \\
\hline & 1998 & & & 13 & 18 \\
\hline & 2002 & & & 8 & 5 \\
\hline & 2006 & & & 13 & 12 \\
\hline & 2010 & & & 12 & 10 \\
\hline PDS & 1990 & & & & 14 \\
\hline PPR & 1994 & & & & 9 \\
\hline PPB & 1998 & & & & 16 \\
\hline PPB & 2002 & & & & 13 \\
\hline \multirow[t]{2}{*}{ PP } & 2006 & & & & 11 \\
\hline & 2010 & & & & 8 \\
\hline
\end{tabular}

FONTE: A autora, a partir de dados do Tribunal Superior Eleitoral (TSE), Schmitt (2000), Carreirão (2006) e Nicolau (2006). 
ELECTORAL COALITIONS: TRENDS AND RACIONALITIES IN FEDERAL AND MAJORITARY STATE ELECTIONS (1990-2010).

\section{Geralda Luiza de Miranda}

This article analyzes the electoral coalitions established to the Presidency of the Republic, Federal Senate, Chamber of Deputies and governatorates in the period of 1990 to 2010. The objective is to evaluate the presence of trends and rationalities in the coalitionist behavior of the parties in these elections. The hypothesis that guides such analyzis is that the emergence of institutional and political incentives, replicate, in the coalitions established in the in the last, the preferences and oppositions exercised on the first. In the data analysis, are taken as units of analysis the coalitions and alliances, and the parties are classified as relevants or micros, according to Giovanni Sartori's terms. The study has allowed to verify consistant trends in the electoral participation of both types of party and, in respect to the rationality of the coalitionist strategies, patterns of different behaviour among the parties, and the main contenders for the presidencial post and their most loyal allies replicate, in the coalitions established to the other posts, the same racionality imposed in the coalitions of the presidential dispute. In general terms, this study proves and qualifies thesis already existant in the literature and elaborate new ones, in particular, concerning the rationality that guides the main federal coalitions is replicated, by a significant number of the parties that compose the system, in the federal legislative and majoritary state elections, also that the traditional ideological resistance among the brasilian parties, in the formation of electoral coalitions, has been subsomed in a political resistance.

KEYWORDS: electoral coalitions; brazilian party system; elections; electoral alliances; electoral behavior. 